\title{
Standardized Measures of Coastal Wetland Condition: Implementation at a Laurentian Great Lakes Basin-Wide Scale
}

\author{
Donald G. Uzarski ${ }^{1}$ • Valerie J. Brady ${ }^{2}$ • Matthew J. Cooper ${ }^{3,4}$ • Douglas A. Wilcox ${ }^{5}$. \\ Dennis A. Albert ${ }^{6} \cdot$ Richard P. Axler $^{2} \cdot$ Peg Bostwick $^{7} \cdot$ Terry N. Brown $^{2}$ • \\ Jan J. H. Ciborowski ${ }^{8}$ • Nicholas P. Danz ${ }^{9}$ • Joseph P. Gathman ${ }^{10}$ • \\ Thomas M. Gehring ${ }^{1}$ • Greg P. Grabas ${ }^{11}$ • Anne Garwood ${ }^{7} \cdot$ Robert W. Howe $^{12}$. \\ Lucinda B. Johnson ${ }^{2}$ - Gary A. Lamberti ${ }^{3}$ - Ashley H. Moerke ${ }^{13}$ - Brent A. Murry ${ }^{1}$. \\ Gerald J. Niemi $^{2}$ • Christopher J. Norment ${ }^{5}$ - Carl R. Ruetz III ${ }^{14}$ - Alan D. Steinman ${ }^{14}$. \\ Douglas C. Tozer ${ }^{15}$ • Ryan Wheeler ${ }^{1}$ - T. Kevin O'Donnell ${ }^{16} \cdot$ John P. Schneider $^{16}$
}

Received: 28 October 2014 / Accepted: 27 September 2016/Published online: 10 October 2016

(C) The Author(s) 2016. This article is published with open access at Springerlink.com

\begin{abstract}
Since European settlement, over $50 \%$ of coastal wetlands have been lost in the Laurentian Great Lakes basin, causing growing concern and increased monitoring by government agencies. For over a decade, monitoring efforts have focused on the development of regional and organism-specific measures. To facilitate collaboration and information sharing between public, private, and government agencies throughout the Great Lakes basin, we developed standardized methods and indicators used for assessing wetland condition. Using an ecosystem approach and a stratified random site selection process, birds, anurans, fish, macroinvertebrates, vegetation, and physico-chemical conditions were sampled in coastal wetlands of all five Great Lakes including sites from the United States and Canada. Our primary objective was to implement a
\end{abstract}

Donald G. Uzarski

uzars1dg@cmich.edu

1 Institute for Great Lakes Research and CMU Biological Station, Central Michigan University, Mt. Pleasant, MI, USA

2 Natural Resources Research Institute, University of Minnesota Duluth, Duluth, MN, USA

3 University of Notre Dame, Notre Dame, IN, USA

4 Present address: Burke Center for Freshwater Innovation, Northland College, Ashland, WI, USA

5 Department of Environmental Science and Biology, SUNY College at Brockport, Brockport, NY, USA

6 Oregon State University, Corvallis, OR, USA

7 Michigan Department of Environmental Quality, Lansing, MI, USA standardized basin-wide coastal wetland monitoring program that would be a powerful tool to inform decision-makers on coastal wetland conservation and restoration priorities throughout the Great Lakes basin.

Keywords Ecosystem health $\cdot$ Wetlands $\cdot$ Indices of biotic integrity · Great Lakes · Disturbance · IBI · Stressor · Monitoring

\section{Introduction}

Coastal wetlands play an essential role in maintaining the health of the Laurentian Great Lakes ecosystem but have be-

8 University of Windsor, Windsor, ON, Canada

9 University of Wisconsin-Superior, Superior, WI, USA

10 University of Wisconsin-River Falls, River Falls, WI, USA

11 Environment and Climate Change Canada, Toronto, ON, Canada

12 University of Wisconsin-Green Bay, Green Bay, WI, USA

13 Aquatic Research Laboratory, Lake Superior State University, Sault Ste. Marie, MI, USA

14 Annis Water Resources Institute, Grand Valley State University, Muskegon, MI, USA

15 Bird Studies Canada, Port Rowan, ON, Canada

16 U. S. Environmental Protection Agency, Great Lakes National Program Office, Chicago, IL, USA 
come imperiled due to anthropogenic influences. These wetlands function as habitat for many endangered species, support and maintain high biodiversity, provide valuable ecological services, are a major component in nutrient cycling, and filter pollutants and toxicants that would otherwise enter the Great Lakes (Burton 1985; Heath 1992; Mitsch and Gosselink 1993; Woodward and Wui 2001; Leveque et al. 2005). In the United States, more than $50 \%$ of wetland area has been lost post European settlement (Burton 1985; Krieger et al. 1992; SOLEC 2007). Additionally, anthropogenic influences are suspected to have negatively affected most wetlands in some way (Bedford 1992; Wilcox 1995; Cooper et al. 2014; Schock et al. 2014). In light of the magnitude of wetlands' role in maintaining the health of the Great Lakes ecosystem, recent efforts have focused on the development of tools to evaluate and track the relative condition of those that remain.

Initial efforts in assessing the condition of aquatic habitat types relied heavily on water chemistry measurements and later expanded to include organism-based indicators and gradients of anthropogenic disturbance. The utility of water chemistry measurements alone, while statistically valid and legally defensible, was limited because specific anthropogenic disturbances often cannot be related to water chemistry and often are ephemeral in nature but leave long-lasting effects (Herricks and Schaeffer 1985). The use of multiple organism-based metrics, such as indices of biotic integrity (IBI), was introduced in the early 1980s by Karr (1981). This approach relied on inferring that measurable biotic community attributes are responses to varying levels of anthropogenic disturbance. Since the 1980s, numerous organism-based indicators have been developed or evaluated for several Great Lakes ecosystem types, including coastal wetlands (Burton et al. 1999; Herman et al. 2001; Simon et al. 2001; Wilcox et al. 2002; Lougheed and Chow-Fraser 2002; Uzarski et al. 2004, 2005, 2014; Chow-Fraser 2006; Seilheimer and Chow-Fraser 2006; Albert et al. 2007; Croft and Chow-Fraser 2007; Howe et al. 2007a, b; Niemi et al. 2007; Martínez-Crego et al. 2010; Grabas et al. 2012; Calabro et al. 2013; Chin et al. 2015). These indicators have been calibrated against both water chemistry attributes and anthropogenic land-use gradients to relate specific biological community characteristics to anthropogenic disturbances across the Great Lakes basin. However, a standardized set of methods for the evaluation of Great Lakes coastal wetlands had not been established.

The characteristics of an effective ecosystem indicator have been previously described as the "identification of the appropriate context (spatial and temporal) for the indicator, a conceptual framework for what the indicator is indicating, integration of science and values, (and) validation of the indicator" (Niemi and McDonald 2004). We believe that the methods described in this paper display these characteristics: 1) the monitoring design and wetland selection technique effectively incorporates both spatial and temporal variation so assessments of current status and trends over time can be made; 2 ) qualitative ratings for each indicator assess the relative condition of each wetland and indicate potential responses to a range of anthropogenic disturbances; 3 ) these methods were developed based on contributions of a bi-national (U.S. and Canada) team of over 150 participants representing more than 50 organizations (Federal, State/Provincial, Academic, NGOs); and 4) the indicators described in this article have either been validated and passed peer review or are in the process of continuing validation and refinement as this will always continue. The standardized protocols presented here will aid policy-makers and managers to make scientifically-validated, well-informed conservation or restoration decisions. The basin-wide standardization of protocols allows for monitoring efforts to be effectively coordinated among organizations. This framework will be useful to generate and answer future research questions, as well as to guide wetland restoration and assess its success.

The goal of this article is to outline standardized, basinwide coastal wetland monitoring methods used to inform decision-makers on coastal wetland conservation and restoration priorities throughout the Great Lakes basin. The methods detailed in this paper include a suite of organism-based indicators that were developed, tested, and scientifically validated by the Great Lakes Coastal Wetland Consortium (Burton et al. 2008) initially, and then tested and altered to some degree, using a combination of physico-chemical parameters in conjunction with land use/cover data to train metrics, from 2011 through 2015 with substantially more data than had ever been collected before. This work also served as an 'Intensification' of the USEPA National Wetland Condition Assessment established in 2011 ( https://www.epa.gov/national-aquaticresource-surveys/nwca ). These methods document procedures for stratified-random site selection of coastal wetlands across the entire Great Lakes basin, collection of biotic data with supporting water quality measurements, and corresponding calculations for bird-, anuran-, fish-, macroinvertebrate- and macrophyte-based indicators. These methods were incorporated into a Great Lakes Basin-scale monitoring program that began in 2011 to assess conditions in all major Great Lakes coastal wetlands (approx. 1000 wetlands) every 5 years. While this monitoring program was specific to the Laurentian Great Lakes, the methodology presented here is broadly applicable to coastal ecosystems globally.

\section{Methods}

Great Lakes coastal wetlands were defined as: "wetlands under substantial hydrologic influence from Great Lakes waters" (McKee et al. 1992). Great Lakes coastal wetlands sampled using these methods were further classified into major types: lacustrine (including open and protected embayments), riverine, or barrier-protected (Albert et al. 2006). A summary of the entire decision-making structure can be found in Fig. 1. 


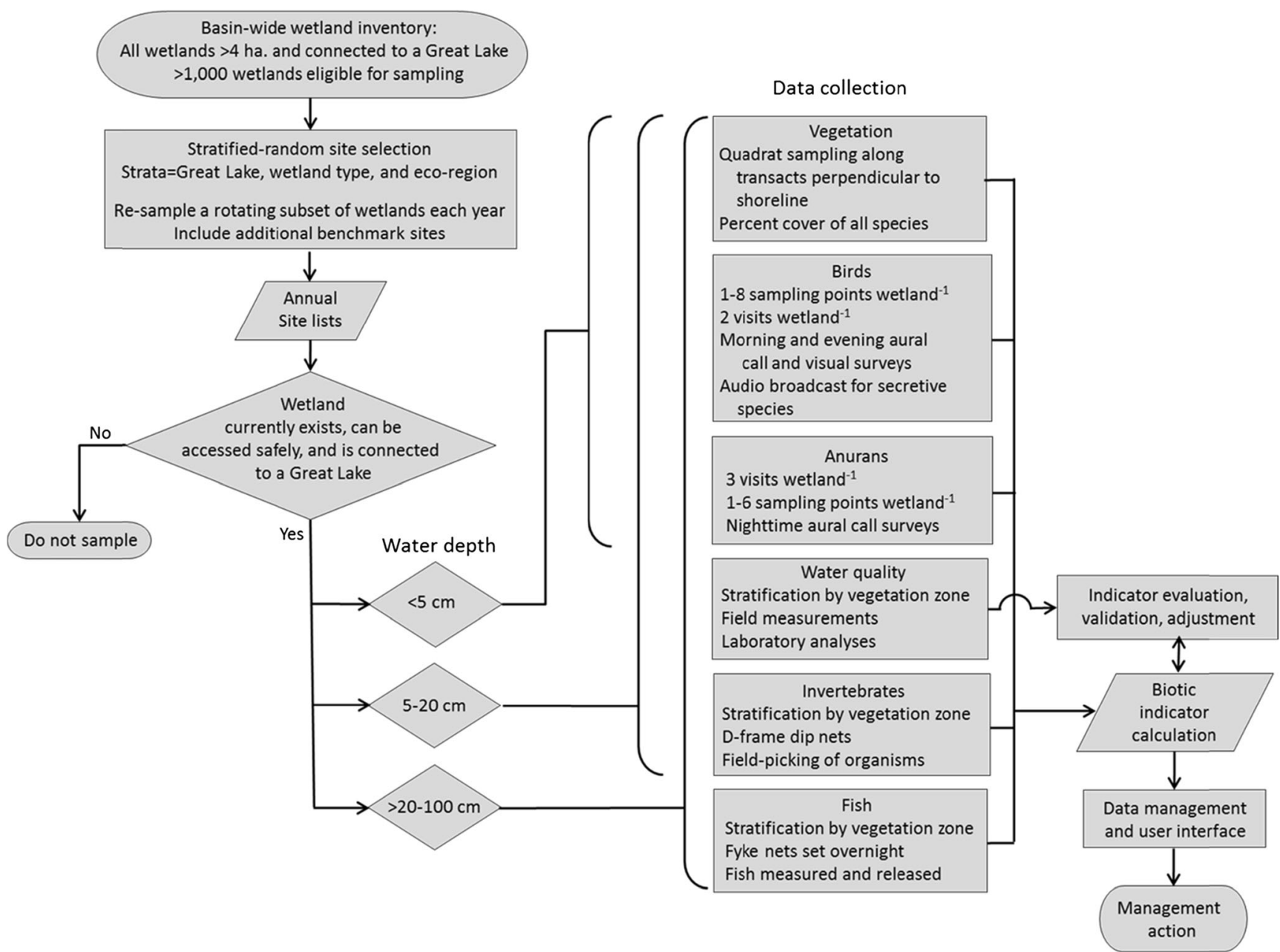

Fig. 1 A conceptual drawing and decision tree addressing the entire process of measuring ecosystem health at Great Lakes coastal wetlands. Once biotic indicator calculations have been made and these data are in

\section{Sampling Design}

The indicators used to evaluate the relative condition of Great Lakes coastal wetlands were applied to subsets of the sampling population of wetlands selected each year via the statistically-robust, stratified probabilistic design proposed by the Great Lakes Coastal Wetlands Consortium (Burton et al. 2008). All coastal wetlands within the Great Lakes basin $>4$ ha in area with a surface-water connection to the Great Lake were included in the selection process (Fig. 2). Wetland size was determined from Ingram et al. (2004). Upland sampling boundaries were determined by either the higher elevation swamp portion of the wetland, as the study was focused only on marshes, or the dominance of woody vegetation. Boundaries were further defined where either hydrological barriers existed, or riverine systems bisected wetland habitat. The lake littoral zone boundary was determined where either emergent vegetation or dense submerged aquatic vegetation (SAV) was no longer present. Sampling was done well within wetlands to avoid edge effects whenever possible. the data management and use interface system, managers can us the decision support tool (DST) to make protection and restoration decisions

Wetland map images were digitized using GIS software (Albert and Simonson 2004; Ingram et al. 2004). Random site selection was stratified by wetland type (riverine, lacustrine, and barrier protected), region (northern or southern), and Great Lake. Approximately $20 \%$ of all wetlands in each stratum were assigned to be sampled each year so that nearly all wetlands within the Great Lakes basin meeting the selection criteria would be sampled within five years (2011-2015). Moreover, wetlands sampled in the first year were used as the starting point for a rotating panel design in which $10 \%$ of wetlands sampled in subsequent years were resampled from the previous years to assess temporal trends in wetland condition. Additional "benchmark" wetlands within each stratum, representing the least impacted and most disturbed wetlands along an established anthropogenic disturbance gradient, were selected each year (Danz et al. 2005). These wetlands were either used as endpoints to calibrate indicator metrics along the gradient of anthropogenic stress for each group or to aid in documenting the effectiveness of restoration or conservation activities. Benchmarks did not have to meet selection criteria 


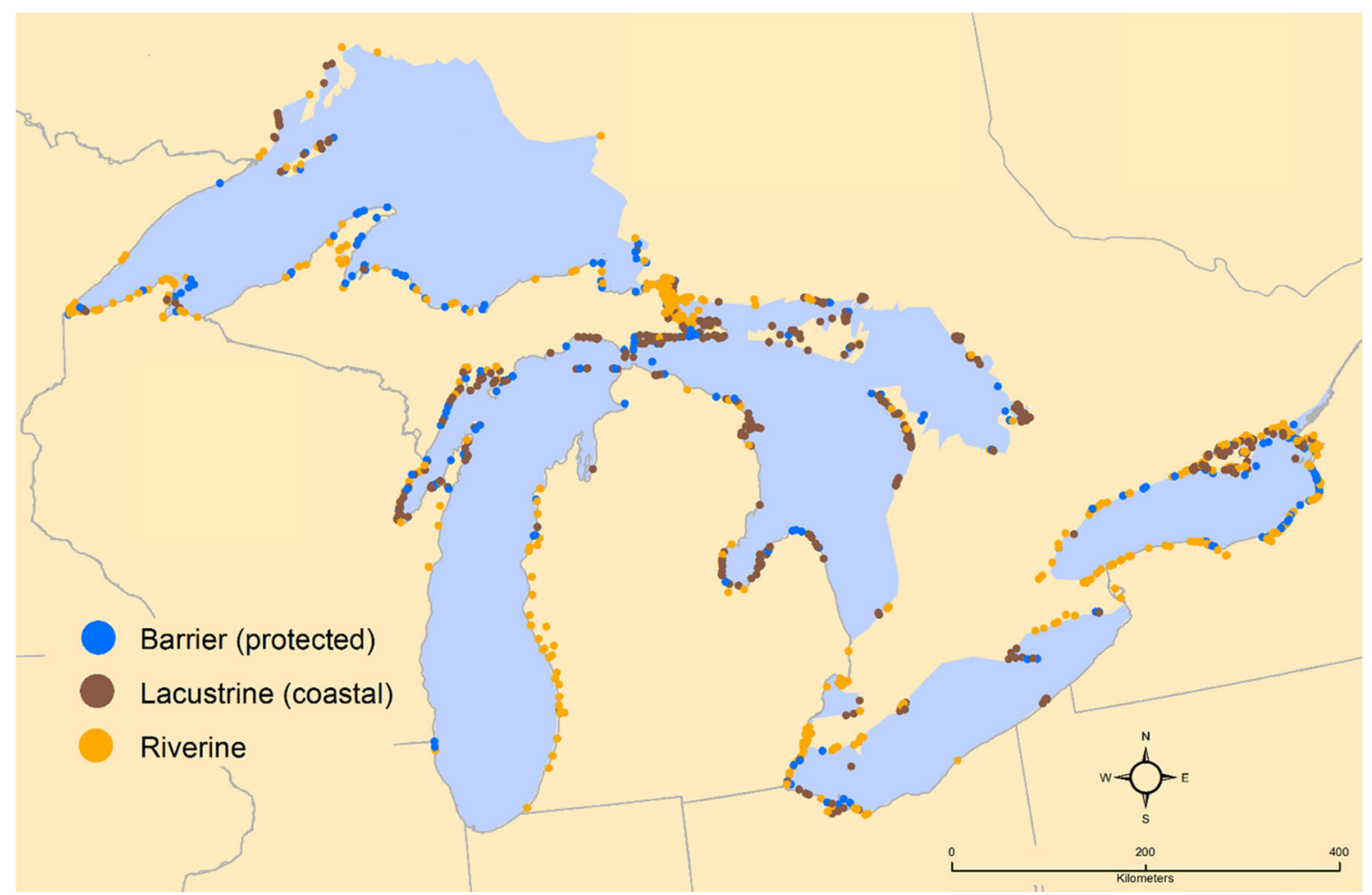

Fig. 2 A map of all Great Lakes coastal wetlands that met the sampling criteria of being at least 4 ha in area with a surface-water connection to a Great Lake or connecting waters. Sites are color coded based on wetland type, barrier protected, lacustrine, or riverine

but instead, sites were selected that represented the most and least amount of anthropogenic disturbance. Some of the former sites contained dikes severing surface-water connections with the Great Lakes, as well as, total removal of vegetation. These data were maintained outside of our experimental design for analysis purposes.

\section{Data Collection}

\section{Chemical and Physical}

Chemical and physical variables were measured within each mono-dominant plant zone of each wetland, simultaneously and co-located with each fish and aquatic macroinvertebrate sample location (Fig. 3). In areas where it was too shallow to sample fish, chemical and physical variables were sampled with invertebrate samples. Vegetation zones were defined as patches of macrophytes in which a single genus, visually estimated, represented at least $75 \%$ of the floating or emergent plant community. An SAV zone was also established where SAV was present but no floating or emergent vegetation was present. Additionally, all vegetation zones had water at least $5 \mathrm{~cm}$ deep at the time of sampling and were at least $400 \mathrm{~m}^{2}$ in area. Separated smaller patches of the same dominant plant morpho-type were considered vegetation zones if no single patch was smaller than $25 \mathrm{~m}^{2}$ and if, when combined, their area was greater than $400 \mathrm{~m}^{2}$ in cumulative area. Chemical and physical variables were used as covariates to explain statistical variability among sites and to establish disturbance gradients designed to check and modify biotic metrics. Water samples and in situ physico-chemical measurements were collected immediately upon arrival at each wetland (generally mid to late morning, but the timing of collection could not be standardized do to logistical reasons), taking care to avoid sample contamination from disturbing the substrate. Sampling took place during June-September starting in the south and moving north to follow phenology as vegetation matured.

In situ water quality variables were measured at the middepth of the water column within each designated vegetation zone using a water quality sonde (e.g., Yellow Springs Instruments model 6600). Measurements usually included temperature $\left({ }^{\circ} \mathrm{C}\right)$, dissolved oxygen $(\mathrm{mg} / \mathrm{L}$ and \% saturation), chlorophyll $a(\mathrm{mg} / \mathrm{L})$, oxidation-reduction potential $(\mathrm{mV})$, total dissolved solids $(\mathrm{mg} / \mathrm{L})$ color (Platinum Cobalt Units; PCU), turbidity (Nephelometric Turbidity Units; NTU), pH (Std units), and specific conductance $(\mu \mathrm{S} / \mathrm{cm})$. When a multi-parameter sonde was not available, at a minimum, temperature, dissolved oxygen, $\mathrm{pH}$, and specific conductance were collected at each set of fish and/or aquatic macroinvertebrate sample locations. Except for temperature, the sensors for the required measurements were calibrated daily using the saturated air method (dissolved oxygen), a three-point calibration $(\mathrm{pH})$, and a two-point calibration (specific electrical conductivity). Consistency across different sensor manufacturers 


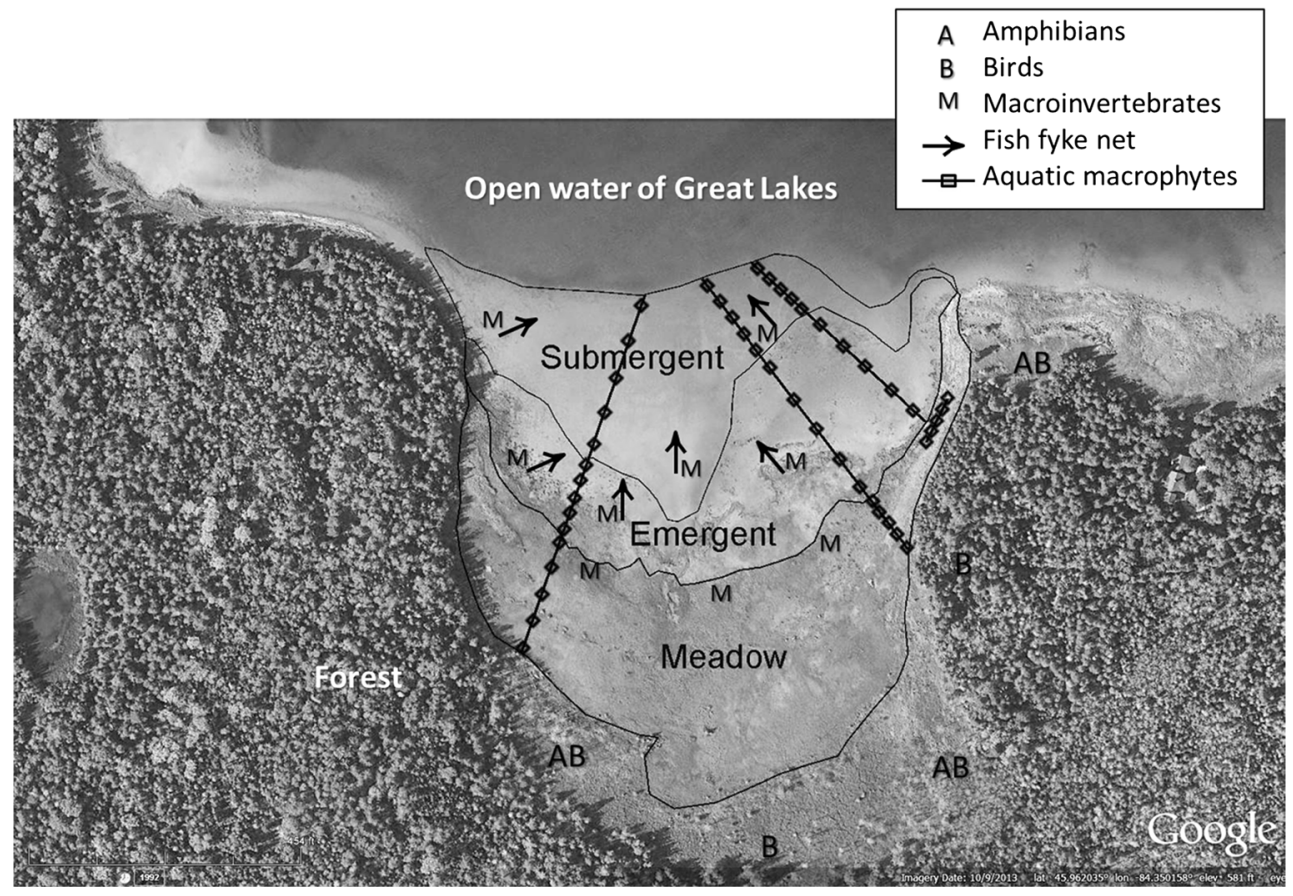

Fig. 3 How an idealized coastal wetland would be sampled by each taxonomic group (aerial photo). Bird and amphibian points are listening points spread around the wetland at the shoreline, with number of points dependent on wetland size and road access. Aquatic macrophyte samples are collected using quadrats placed along transects perpendicular to shore through the three major vegetation zones typical of wetlands (wet meadow, emergent, and submergent). Fish and macroinvertebrate sample points are placed based on monodominant plant morphotypes

was maintained by strict adherence to a detailed quality assurance project plan (QAPP) that all field staff followed (http://greatlakeswetlands.org). Temperature was compared to multiple hand-held thermometers.

Water samples were collected at each of the three fish and/ or aquatic macroinvertebrate sample locations. At each sampling point, two successive $1 \mathrm{~L}$ samples were taken at middepth, by forcing the bottle, open side up, stringently below the surface to avoid collecting surface films. The $1 \mathrm{~L}$ acidwashed polypropylene bottle was attached to the end of an extension pole. To remove debris from the sample, each sample was pre-filtered through an acid-washed polypropylene funnel with $500 \mu \mathrm{m}$ mesh as it was poured into a $10 \mathrm{~L}$ acidwashed polypropylene carboy. The resulting $6 \mathrm{~L}$ composite sample was thoroughly mixed, added to a $4 \mathrm{~L}$ acid-washed, deionized water (DI) rinsed, polypropylene Cubitainer7, and held on ice in the dark in insulated coolers for later analyses in the field or following transport to the laboratory. The remaining sample in the carboy was mixed and used to measure water clarity with a $100 \mathrm{~cm}$ transparency tube (Anderson and Davie 2004). If more than one mono-dominant plant zone was sampled in a single wetland, the carboy, funnel, and collection bottle were each emptied and rinsed with surface-water three times before repeating the sampling procedure at subsequent plant zones. (not easily visible). Water quality and habitat parameters are measured at each fish fyke net and/or macroinvertebrate sampling point. Macroinvertebrates are always sampled near fyke net locations, but macroinvertebrate samples may also be collected by themselves in vegetation morophotypes where the water is too shallow for fyke nets. See text for complete description of sample point locations for each taxonomic group. Only herbaceous vegetation areas are sampled in each wetland

Further handling and analysis of each $4 \mathrm{~L}$ Cubitainer sample involved conducting time-sensitive analyses in the field or by preparing samples for storage and analytical testing. Within $12 \mathrm{~h}$ of sample collection, alkalinity $\left(\mathrm{mg} / \mathrm{L} \mathrm{CaCO}_{3}\right)$ was determined by titrating raw water with standardized sulfuric acid ( 2 end-point titration, APHA 2005). Two raw water samples were added to $250 \mathrm{~mL}$ acid-washed polypropylene bottles and stored frozen until total nitrogen $(\mathrm{mg} / \mathrm{L})$ and total phosphorus $(\mathrm{mg} / \mathrm{L})$ were measured in the laboratory via standard methods (APHA 2005). A measured 300-1000 mL sample of raw water for chlorophyll determination was filtered in subdued light through a DI water rinsed 47- or $42.5 \mathrm{~mm}$ Whatman GF/C glass fiber filter into an acid-cleaned, DI-rinsed filtration funnel and flask. Using forceps to avoid contamination, the filter was folded twice, wrapped in labeled aluminum foil, and frozen within a small zip-seal plastic bag, within a wide-mouth polypropylene bottle to avoid melt-water contamination. The filter was later thawed for chlorophyll $a$ extraction in the laboratory using standard methods (APHA 2005). A $250 \mathrm{~mL}$ volume of $\mathrm{GF} / \mathrm{C}$ filtrate from the aforementioned filtration was further filtered through an acid- and DI rinsed $0.45 \mu \mathrm{m}$ Millipore (or equivalent) membrane filter into an acid-washed, DI-rinsed polypropylene bottle, and frozen. The filtration apparatus was acid-washed and rinsed between samples. This sample was later thawed and used to determine concentrations 
of soluble reactive phosphorus ( $\mathrm{SRP}, \mathrm{mg} / \mathrm{L}$ ), ammonium- $\mathrm{N}$ $(\mathrm{mg} / \mathrm{L})$, and [nitrate + nitrite]- $\mathrm{N}(\mathrm{mg} / \mathrm{L})$ via standard methods (APHA 2005). When logistically possible, $500 \mathrm{ml}$ volume of $0.45 \mu \mathrm{m}$ filtrate was analyzed to determine concentrations of select anions (chloride $[\mathrm{mg} / \mathrm{L}]$, fluoride $[\mathrm{mg} / \mathrm{L}]$, and sulfate $[\mathrm{mg} / \mathrm{L}])$ and determine true color (PCU) via standard methods (APHA 2005).

\section{Vegetation Sampling}

Sampling for each wetland occurred along three transects that were established perpendicular to the depth contours of the wetland, crossed through selected vegetation zones, and were greater than $20 \mathrm{~m}$ apart. Transect starting locations were selected to provide a representative sample of the floral composition of the wetland, with exact starting points randomly selected. Vegetation sampling included a wider range of habitats in the wetland than for other taxa that require standing water (fish and macroinvertebrates). For this indicator, major vegetation zones were defined differently than those used for all other methods described. These vegetation zones were defined as the wet meadow (WM) zone, emergent vegetation zone, and SAV zone. Treed swamp and shrub thicket zones were not sampled and were not often lake-influenced at current lake levels. Each transect consisted of five quadrat sampling points per vegetation zone that were evenly spaced and centered between the boundaries of each vegetation zone. A maximum of 15 quadrat sampling points per transect was sampled if all vegetation zones were present. Vegetation was surveyed in $1 \mathrm{~m}^{2}$ quadrats at each sampling point along each transect, for a total of 15-45 quadrats per wetland (depending on number of zones). All survey quadrats were placed $2 \mathrm{~m}$ to the side of the transect line to avoid trampling effects. A width of $11 \mathrm{~m}$ was used as a zone width threshold since that was the smallest width to accommodate five $1 \mathrm{~m}^{2}$ quadrats with a $1 \mathrm{~m}$ distance between quadrats and the zone boundaries. If the width of a vegetation zone was less than $11 \mathrm{~m}$, a perpendicular transect was established at the midpoint of the zone along the original transect and quadrats were then placed at $5 \mathrm{~m}$ intervals along the perpendicular transect in the narrow vegetation zone (Fig. 3). Narrow zones were more likely encountered in wet meadow and submergent marsh communities. Percent cover for each plant species, total percent vegetation cover, water depth $(\mathrm{cm})$, organic sediment thickness $(\mathrm{cm})$, and estimated relative turbidity were recorded for each quadrat. Plant species were identified using region-specific taxonomic keys such as Great Lakes floras (Voss 1972a; b; Voss 1985; Voss 1996; Chadde 2011; Voss and Reznicek 2012). Representative specimens of plants that could not be identified in the field were collected and preserved for identification in the laboratory. Vegetation surveys were conducted in June-August during the period of maximal vegetative growth to capture the full extent of the community. Some sterile or immature organisms could not be identified to species and were not used in the indicator calculations. Almost all invasive, non-native species could be recognized, even if sterile, and were included in the analyses.

\section{Macroinvertebrate Sampling}

Aquatic macroinvertebrates were sampled following Burton et al. (2008) macroinvertebrate-based indicator protocol (Uzarski et al. 2004) with slight variations. Samples were collected each year within the vegetation zones of each wetland (described for water-quality sampling) from mid-June through early September; sampling started earlier in the southern Great Lakes and moved northward with phenology. Because macroinvertebrate communities and habitat structure vary as a function of wave exposure (Cardinale et al. 1998; Cooper et al. 2012, 2014), the Schoenoplectus (bulrush) vegetation zone was divided into two stem density-dependent classes that were considered different vegetation types because of the manner in which dense stands inhibit water movement. These two zones were defined as the shoreward "inner Schoenoplectus" zone consisting of $>25 \mathrm{stems} / \mathrm{m}^{2}$, and the "outer Schoenoplectus" zone, closer to the open water and consisting of $<25 \mathrm{stems} / \mathrm{m}^{2}$.

Macroinvertebrates were collected at three haphazardly selected sampling points (i.e., replicates) within each vegetation type, with a minimum of $15 \mathrm{~m}$ between replicates. Whenever possible, macroinvertebrate sample collections were colocated with fish sampling points. However, patch size and water-depth criteria occasionally did not allow for fish sampling. Sampling points were positioned well within each vegetation zone to avoid edge effects (Cooper et al. 2012). Samples were collected using standard $0.5 \mathrm{~mm}$-mesh Dshaped dip nets with mouths approximately $30 \mathrm{~cm}$ wide by $16 \mathrm{~cm}$ tall. Dip net sweeps were taken through the entire water column and involved working from the substrate up through the water column to the surface, in the process gently agitating the top surface of the substrate and brushing plant stems. Each sweep covered approximately $1 \mathrm{~m}$, and the number of sweeps taken at each sampling point was recorded. Dip net sweep contents at each sampling point were field-picked by combining the contents of the dip net and spreading those contents evenly into gridded $(5 \times 5 \mathrm{~cm})$ white trays $\sim 20 \mathrm{~cm} \times 35 \mathrm{~cm} \times 5 \mathrm{~cm}$ in size. A representative sample of macroinvertebrates was collected by systematically picking all individuals from each $5 \times 5 \mathrm{~cm}$ grid square before moving on to the next square. Macroinvertebrates were picked using fine forceps and immediately placed into storage vials containing $95 \%$ ethanol. Picking was conducted until 150 individuals were collected or until the sum effort of all persons picking reached $30 \mathrm{~min}$ (e.g., 3 persons $\times 10 \mathrm{~min}=30$ person-minutes), at which time, additional macroinvertebrates were picked until the next multiple of 50 was obtained regardless of the time that was required 
to do so. Microcrustacea and zooplankton (e.g., rotifers, cladocerans, copepods) were intentionally avoided during picking because they are poorly sampled with $0.5 \mathrm{~mm}$ mesh nets. Macroinvertebrates were later identified in the laboratory to the lowest operational taxonomic unit (usually the genus level) using 8-50× stereomicroscopes and standard taxonomic keys (Primarily Merritt et al. 2008 and Thorp and Covich 2010). The exceptions and corresponding taxonomic resolution were as follows: Curculionidae, Chrysomelidae, Hirudinea, Hydrobiidae, and Psidiidae (family); Brachycera, Stratiomyidae, Muscidae, Ephydridae, and Chironomidae (sub-family); Acari (super-family); Collembola and Oligochaeta (order); Turbellaria (class); and Nematomorpha (phylum). Identification QA/QC was conducted via secondary blind peer review, and discrepancies were resolved by consulting third-party expert taxonomists (http:/greatlakeswetlands. org).

\section{Fish Sampling}

Samples were collected within the vegetation zones of each wetland concurrently with macroinvertebrate sampling (Fig. 3). Vegetation types for this protocol were defined consistent with those used for water quality and macroinvertebrate protocols. However, fish sampling required water depths between 25 and $100 \mathrm{~cm}$ and a vegetation specific area of at least $400 \mathrm{~m}^{2}$. Smaller patches could be used if the combined area of a vegetation type was at least $400 \mathrm{~m}^{2}$ and no patch was smaller than $100 \mathrm{~m}^{2}$. Schoenoplectus vegetation zones were again separated into inner Schoenoplectus $\left(>25 \mathrm{stems} / \mathrm{m}^{2}\right.$ ) and outer Schoenoplectus $\left(<25 \mathrm{stems} / \mathrm{m}^{2}\right)$ zones. A full list of vegetation types can be found at (http://greatlakeswetlands.org).

Fish were collected at three sampling points (i.e., replicates) within each vegetation type. The spacing between sampling points was at minimum $25 \mathrm{~m}$. Fish samples were collected passively using one of two sizes of fyke (i.e., trap) nets positioned at each sampling point, so that the lead extended as far into the vegetation type as possible, perpendicular to the shoreline. Nets were set to sample fish using a vegetation morphotype as habitat. For narrow zones $(<5 \mathrm{~m})$, leads were oriented at an angle required to fit the entire lead within the plant zone (i.e., leads were not shortened) while also spanning the zone's entire width. Large-sized fyke nets consisted of a $7.62 \mathrm{~m}$ (length) $\times 0.91 \mathrm{~m}$ (height) lead extended from the opening of a $1.22 \mathrm{~m}$ (width) $\times 0.91 \mathrm{~m}$ (height) box frame. The box frame had $1.83 \mathrm{~m}$ (length) $\times 0.91 \mathrm{~m}$ (height) wings that extended on either side at about a $45^{\circ}$ angle from the direction of the lead and was followed by five $0.76 \mathrm{~m}$ diameter hoops that terminated in a closable cod-end. The inner diameter of the mesh funnels on the first and third hoops was $0.17 \mathrm{~m}$ and the mesh funnels were oriented toward the codend. Small-sized fyke nets, which were essentially the same configuration as the large fyke nets, consisted of a $7.62 \mathrm{~m}$ (length) $\times 0.46 \mathrm{~m}$ (height) lead extended from the opening of a $0.91 \mathrm{~m}$ (width) $\times 0.46 \mathrm{~m}$ (height) box frame. The box frame had $1.83 \mathrm{~m}$ (length) $\times 0.46 \mathrm{~m}$ (height) wings extended on either side at $45^{\circ}$ from the direction of the lead, followed by five $0.10 \mathrm{~m}$-diameter hoops, and ending with a closable codend. The inner diameter of the mesh funnels was $0.10 \mathrm{~m}$, and the mesh funnels were positioned on the first and third hoops and oriented toward the cod-end. Leads and wings for large and small fyke net sizes were equipped with bottom weights and top floats, and all nets were constructed with $4.8 \mathrm{~mm}$ mesh. Large and small fyke nets were used to fish vegetation zones with water depths from 0.5 to $1 \mathrm{~m}$ and from 0.25 to $0.5 \mathrm{~m}$, respectively. Nets were fished overnight and for a minimum of $12 \mathrm{~h}$. If less than 10 fish in total were captured from all three nets fished in a single vegetation zone, these data were discarded and the nets were re-set for an additional night. All fish >20 mm total length (TL) were identified to species using basin-specific taxonomic keys (e.g., Bailey et al. 2004; Hubbs et al. 2004; Holm et al. 2009; Corkum 2010), examined for deformities and parasites, and a haphazard subsample of the first 25 individuals of each species and size group (small [presumably age 0 or juveniles] and large [presumably at least age 1 or adults]) were measured for TL (mm) and released (except for individuals difficult to identify in the field or individuals saved for a voucher collection).

\section{Anuran and Bird Sampling}

The basic sampling unit used for both anurans and breeding birds was a point count, typically from a location predetermined through a geographic information system and adjusted if necessary based on local conditions and access. The study unit was the wetland and the number of points sampled in a given wetland varied from one to six points for anurans and from one to eight points for birds. The number of sample points in a wetland was influenced by total wetland area, shape, accessibility, and wetland habitat heterogeneity (Conway 2011). Anuran point counts were located a minimum of $500 \mathrm{~m}$ apart and bird point counts were located a minimum of $250 \mathrm{~m}$ apart.

To minimize errors in species identification or in data entry, all anuran and bird field personnel were tested and trained prior to the field season, regardless of their previous experience. Qualifications for conducting our protocols included: 1) ability to visually identify $95 \%$ of 20 bird images of species that are characteristic of wetland habitats and are likely to be seen rather than heard in Great Lakes wetlands; 2) ability to aurally identify sound segments of $90 \%$ of 30 bird species and $100 \%$ of anuran species; and 3 ) field training ( http://greatlakeswetlands.org ). Field training ensured proficiency in locating predetermined points using global positioning system (GPS) receivers in the field and in properly entering data on field sheets. Field observers were tested with standardized online audio and visual instruments. Recent 
studies (Venier et al. 2012; Rempel et al. 2013) have demonstrated that digital audio recordings can significantly improve the quality of point counts because even expert observers fail to detect some vocalizing species during point counts. At a subset of sites, point counts of both birds and anurans were supplemented with high quality digital recordings, providing an opportunity to assess the completeness of counts used in our data analysis.

Specifics of Anuran Sampling The overall goal of the anuran monitoring program was to document the species present at the respective wetlands during the primary frog and toad mating seasons, which vary among species and from year to year depending on weather conditions between March and July. Given the massive area of the Great Lakes coastline, this monitoring program did not attempt to verify breeding productivity of frog and toad species within these wetlands, which would have required intensive searches for eggs or emergence of individuals from the wetland.

Anuran point counts within each wetland were completed three times (Price et al. 2007): 1) when nighttime air temperatures consistently reached $5^{\circ} \mathrm{C}$, usually in March or April; 2) when nighttime temperatures consistently reached $10^{\circ} \mathrm{C}$ and at least $15 \mathrm{~d}$ from the first sample period (generally April or May); and 3) when nighttime temperatures consistently reached $17^{\circ} \mathrm{C}$ and at least $15 \mathrm{~d}$ from the second sample period (generally June or July). Anuran data were gathered using timed, unlimited-distance counts (full circle) at each point. Point surveys were completed from $0.5 \mathrm{~h}$ before to $4.5 \mathrm{~h}$ after sunset. Counts were not conducted when winds were high (> $20 \mathrm{~km} / \mathrm{h}$ ) or during rain, although sampling during periods of drizzle or light winds was acceptable, especially if anuran calling was deemed normal.

Each anuran survey was $3 \mathrm{~min}$ in duration. Data recorded at each survey point before or immediately after the survey included the following: 1) point ID with recording of the GPS waypoint, 2) date, 3) start time, 4) name of observers (for safety reasons we recommend two individuals participate in the counts), and 5) weather conditions including air temperature, wind speed and direction, precipitation, cloud cover, ambient noise levels, and if possible water temperature. Data recorded during the survey included: 1) identified species; 2) calling intensity (see below) of all frog and toad species, 3 ) the nearest distance of each anuran detection in one of three categories ( $<50 \mathrm{~m}, 50-100 \mathrm{~m}$, or $>100 \mathrm{~m})$, and 4) location of each detection with reference to the observer (semicircle in front of or behind the observer, oriented at a fixed direction facing the wetland). For safety reasons, we recommend only shore-based and no over-water nighttime surveys. Calling intensity for each species was coded according to three categories: Code 1 described a condition where calls were not simultaneous and individuals of a given species could be counted; Code 2 represented a level of activity where some calling was simultaneous, but numbers of individuals could be reliably estimated; Code 3 described a full chorus with so many continuous and overlapping calls that individuals could not be accurately counted.

Specifics of Bird Sampling The overall goal of the breeding bird monitoring program was to identify species that used the wetlands during the primary breeding season (mid-May to mid-July) for nesting, foraging, or resting. As with anurans, the time available to represent the extensive area of the Great Lakes coastline precluded lengthy surveys where nesting by birds within individual wetlands could be confirmed.

Observers sampled each survey point twice during the breeding season, once during the morning ( $30 \mathrm{~min}$ before to $4 \mathrm{~h}$ after sunrise) and once during the evening ( $4 \mathrm{~h}$ before to $0.5 \mathrm{~h}$ after sunset). These point counts were completed a minimum of $15 \mathrm{~d}$ apart, between 20 May and 10 July in the southern portions of the Great Lakes region, and between 10 June and 10 July in the northernmost portions (northern third of Lake Superior).

The duration of each point count was $15 \mathrm{~min}$, consisting of: 0-5 min passive listening, $5 \mathrm{~min}$ of call-broadcasts, and $5 \mathrm{~min}$ of passive listening. Our protocol included call-broadcasts of standard recordings for five species that could be secretive, were known to respond to call-broadcasts, and were of conservation concern in the Great Lakes region (Tozer 2013). These species included in order of call-broadcast sequence were: 1) Least Bittern (Ixobrychus exilis), Sora (Porzana carolina), Virginia Rail (Rallus limicola), a mixture of Common Gallinule (Gallinula galeata) and American Coot (Fulica americana), and Pied-billed Grebe (Podilymbus podiceps). Songs or calls of each species were transmitted for 30 s followed by $30 \mathrm{~s}$ of passive listening before the next species was played. Call-broadcasts were completed by holding the speaker above the vegetation and in the direction facing the primary wetland area. Broadcasts were standardized at $80 \mathrm{db}$ level with minimal distortion or noise and the level checked with a decibel meter ( $1 \mathrm{~m}$ from speaker) before each day of surveys.

During point counts observers recorded all birds that could be detected in any direction (full circle) and at unlimited distance. To permit comparisons of samples centered at the edge of a wetland, a line delineating two equally-sized $180^{\circ}$ areas in front of and behind the observer was drawn on the field form, and all detections were assigned to one or the other hemispheres. This deviated to some extent from previous wetland count protocols, but analysis of a $360^{\circ}$ area better documents bird use of the entire wetland and associated riparian areas. Unlimited distance counts that include distance estimation are preferred for monitoring (Etterson et al. 2009; Matsuoka et al. 2012, 2014). Data recorded at each survey point before or immediately after the survey included: 1) point ID with recording of the GPS waypoint, 2) date, 3) start time, 4) name of 
observer(s), 5) weather conditions including air temperature, wind conditions, precipitation, cloud cover, ambient noise lev$\mathrm{el}$, and if possible water temperature, and 6) verification of whether call-broadcast volume was checked. Data recorded during the survey included: 1) species identified or unknown but to the lowest taxonomic level possible (e.g., unknown waterfowl, unknown bird), 2) the distance of each bird detection $(<50 \mathrm{~m}, 50-100 \mathrm{~m}$, or $>100 \mathrm{~m}), 3)$ the type of detection (e.g., observed, calling, singing, flyover), 4) the minute interval (e.g., 0 for minute $0-1$ ) when the species was first detected, 5) evidence of any breeding activity (e.g., on nest, distraction display, or aggressive territorial behavior), and 6) the hemisphere (in front of or behind the observer) that the bird was first detected.

\section{Indicator Calculations}

\section{Chemical and Physical Data}

Chemical and physical data were combined to establish physico-chemical indicators /disturbance-gradients. Land use/cover data were obtained from existing digitized maps. When land use/cover data from more than one year were available, on-site observations were used to determine the most accurate map. Coarse categories, including agriculture, development, wetlands and natural vegetation (herbaceous, forested, and shrub land combined) were calculated for $1 \mathrm{~km}$ and $20 \mathrm{~km}$ buffers around all non-riverine sites. Land use/ cover was calculated for the entire upstream-watershed at riverine sites (Wolter et al. 2006). All data were verified with onsite observations where possible.

Physico-chemical indicators/disturbance-gradients were established by combining land use/cover and chemical/ physical data for each year. They were established using both principal components (PCs) and by calculating rank sums using all chemical/physical and land use/cover data $(1 \mathrm{~km}$ and $20 \mathrm{~km}$ buffers). Chlorophyll $a$, total phosphorus, total nitrogen, soluble reactive phosphorus, ammonium, water temperature, specific conductance, percent agriculture and percent development were ranked directly with the greater values indicating disturbance. The inverse was true for parameters such as water transparency, total alkalinity, percent natural vegetation, and percent wetland from land use/cover data. Extreme values, either very high or very low, for nitrate-N, percent saturation of dissolved oxygen, and $\mathrm{pH}$ were considered indicators of disturbance. Therefore, absolute values of the difference from the median concentration were used to establish a rank order for each of these parameters. Principal component analyses were also conducted on these data sets, and PC 1 was ranked in an appropriate direction from relatively degraded (high nutrients, agriculture, and urbanization) to relatively pristine (relatively forested and low nutrients). All ranks were then combined to produce a "sumrank", which was scaled from 0 to 100 to produce the final relative indicator. The physico-chemical indicator/disturbance-gradient was used in conjunction with other indicators to determine wetland condition and for training metrics.

\section{Vegetation-Based Indicator}

Total vegetation indicator scores were calculated for each wetland using 10 metrics that collectively evaluated the relative condition of the wetland. Metrics included entire-site and vegetation-zone specific calculations. For each wetland, the above-mentioned vegetation zones remained the same except for the emergent zone. In devising indicator calculations, the emergent zone was divided into dry emergent (DE) and flooded emergent (FE) zones, which were grouped with the wet meadow (WM) and submerged aquatic vegetation (SAV) zones, respectively. Emergent zone quadrats that had $<1 \mathrm{~cm}$ of standing water were included in the DE zone, and quadrats with $\geq 1 \mathrm{~cm}$ of standing water were included in the FE zone. Invasive species and tolerant SAV species were defined based on literature and laboratory studies, as summarized in Albert and Minc (2004).

Calculated individual metrics were assigned numerical scores as described at http://greatlakeswetlands.org . Assigned numerical scores were summed with a maximum possible score of 50. Total vegetation indicator scores were given one of five qualitative ratings based on the following criteria: (0-10) very low quality; (11-20) low quality; (21-30) medium quality; (31-40) moderately high quality; and (41-50 ) high quality.

\section{Macroinvertebrate-Based Indicator}

Total macroinvertebrate indicator scores were calculated for each wetland using vegetation zone-specific sets of metrics. These included nine metrics that collectively evaluated the condition of the wet meadow zone, 12 metrics that collectively evaluated the condition of the inner Schoenoplectus ( $>25$ stems $/ \mathrm{m}^{2}$ ) zone, and 11 metrics that collectively evaluated the condition of the outer Schoenoplectus $\left(<25 \mathrm{stems} / \mathrm{m}^{2}\right)$ zone (http://greatlakeswetlands.org). Data used to calculate each metric were the median values among the three replicate samples for each zone. Medians were used to dampen the effect of outliers. Individual metric scores for each zone were summed with maximum possible scores of 45, 72, and 65 for wet meadow, inner Schoenoplectus, and outer Schoenoplectus, respectively. Total indicator scores were assigned qualitative ratings within proportional ranges (http://greatlakeswetlands.org). If more than one vegetation morphotype was sampled within a given wetland, indicator scores were calculated for each, summed, and divided by the sum of maximum possible scores for all morphotypes sampled. Qualitative ratings were then assigned within the 
established proportional ranges modified from Uzarski et al. (2004) (http://greatlakeswetlands.org).

\section{Fish-Based Indicator}

Total fish-based indicator scores were calculated for each wetland using vegetation morphotype-specific sets of metrics. Fourteen metrics collectively evaluated the condition of the Schoenoplectus zone, and 11 metrics collectively evaluated the condition of the Typha zone (http://greatlakeswetlands. org). In calculating metrics for the Schoenoplectus zone, data from both inner and outer Schoenoplectus sampling points were combined to follow Uzarski et al. (2005), and the average catch per species was used to calculate each metric. Individual metric scores for each zone were summed, with maximum possible scores of 72 and 63 for Schoenoplectus and Typha zones, respectively. Total indicator scores were assigned qualitative ratings within proportional ranges (http://greatlakeswetlands.org). If more than one vegetation morphotype was sampled within a given wetland, indicator scores were calculated for each morphotype, summed, and divided by the sum of maximum possible scores for all zones sampled. Qualitative ratings were then assigned within the established proportional ranges (http://greatlakeswetlands. org).

\section{Anuran- and Bird-Based Indicator}

Results from the anuran and bird point counts have been used to generate a variety of environmental indicator metrics. EC and CLOCA (2004) and Crewe and Timmermans (2005) used species richness and abundance variables for targeted species groups (e.g., marsh-nesting obligates) in a traditional IBI framework (Karr 1981). Smith-Cartwright and Chow-Fraser (2011), following DeLuca et al. (2004), developed wetland scores based on a priori specialist-generalist characteristics of each species present. Howe et al. (2007a, b) described a new framework called the Index of Ecological Condition (IEC) that uses a likelihood approach (Hilborn and Mangel 1997) to estimate ecological health based on occurrences of species with documented responses to specific environmental stressors. This method typically uses presence/absence or abundances of individual species (e.g., Gnass Giese et al. 2015), but also can incorporate multi-species abundances or species richness variables as long as they are specifically linked with a stressor of interest. Smith-Cartwright and Chow-Fraser (2011) and Chin et al. (2015) suggested that the disturbance gradient and indicator approach of Howe et al. (2007a, b) is superior to that of EC and CLOCA (2004), Crewe and Timmermans (2005), and to that of DeLuca et al. (2004) for assessing ecological integrity of Great Lakes coastal wetlands using bird assemblages. Our recent work also suggested that this may extend to anurans. As long as field surveys use the prescribed methods and rigorous sampling standards, future results can be applied to both existing and new indicator metrics. Development of these environmental indicator metrics produced useful results for anurans and birds (Fig. 4) and is an active area of on-going research that will likely continue to improve their utility.
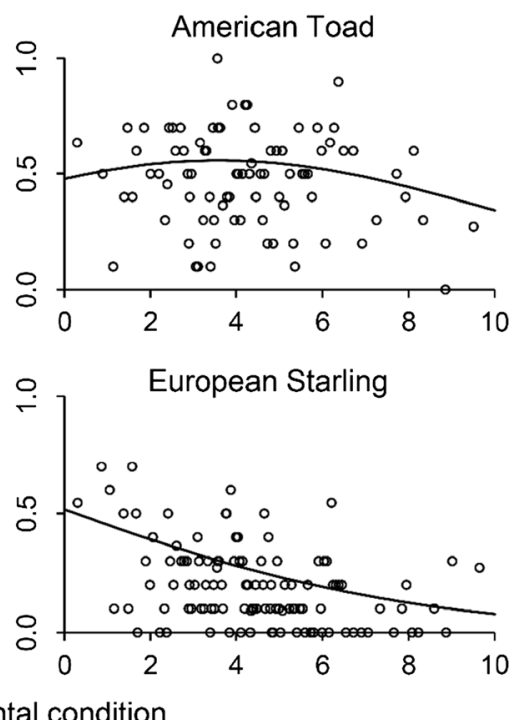

environmental condition due to agriculture, development, and wetland area $(0=$ poor condition, $10=$ good condition). Open circles represent binned data at 10 observations per bin. Spring Peeper $=$ Pseudacris crucifer $;$ American Toad = Anaxyrus americanus; American Bittern = Botaurus lentiginosus; European Starling = Sturnus vulgaris 


\section{Results}

\section{Chemical and Physical Data}

Chemical and physical data collected in 2015 indicated a fairly consistent trend of degraded wetlands in the south to mildly impacted or reference conditions in the north with exceptions in the Duluth, MN area as well as the St. Marys River (Fig. 5). Since water quality varies annually with water level fluctuation, the most recent data available were included. SumRank values from each inundated vegetation zone were averaged for each site. However, water quality varied annually and even within site based on vegetation zone. Examples are shown for sites 461, depicting annual variation, and 974 showing intrawetland variation. Site 461 was a benchmark site so data were available from 2012 to 2015 . Only a single inundated vegetation zone, dense bulrush, was present over this time-period. Water quality increased as water levels increased from 2012 to 2015. In 2015, Site 974 contained two vegetation zones. The protected zone, Peltandra, with less pelagic mixing, was determined to be moderately degraded while the other, sparse bulrush, with a strong connection to the pelagic water of Lake Superior, was reference conditions. The two averaged together produced an overall wetland category of mildly impacted (Fig. 5). These data were important for training metrics as water quality is dynamic and fluctuates with water levels and hydrologic alterations.

\section{Vegetation}

Vegetation metrics from 2011 to 2015 showed a very strong decreasing disturbance gradient from south to north (Fig. 6). The most populated areas across the basin reflected the lowest vegetation scores. This, in part, also reflects a latitudinal gradient associated with the invasive Phragmites australis since metrics were heavily weighted based on the dominance of invaders. During this time-period, the majority of each vegetation transect was not inundated with water, so the metrics were more reflective of disturbance in the higher elevations of the wetlands. The disturbance detected by the vegetation metrics was largely indicative of the spread of invaders during low water periods.

\section{Macroinvertebrates}

Macroinvertebrate metrics were calculated for outer Schoenoplectus, inner Schoenoplectus, and wet meadow from 2011 through 2014 (Fig. 7). The 2015 invertebrate data had not been processed for quality assurance and quality control so these data were not included. Abundant invertebrate data were

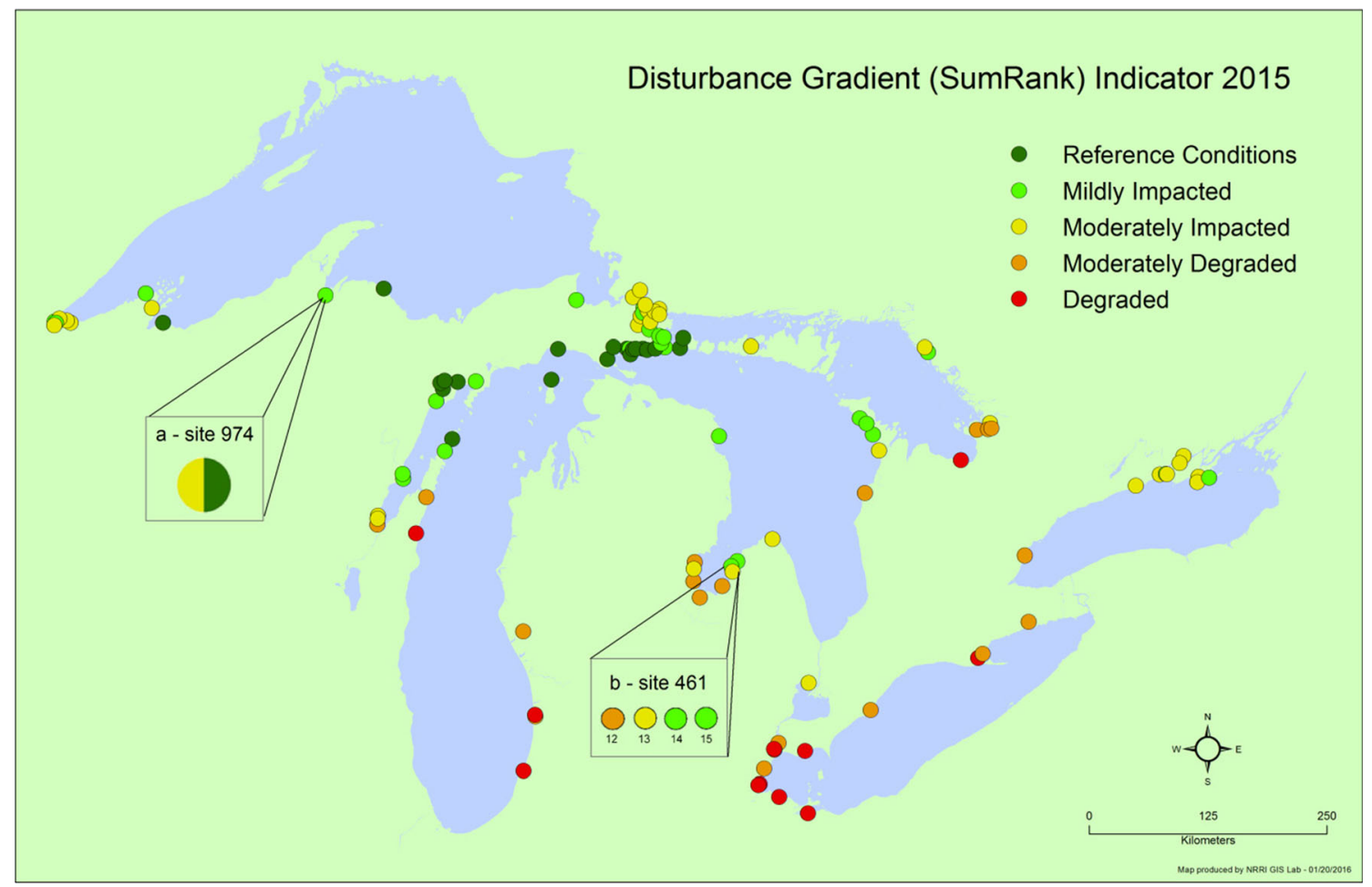

Fig. 5 Physico-chemical data collected in 2015 with dark green representing reference conditions and red indicating degraded. If multiple vegetation zones were sampled at a given site in 2015, they were averaged. Example a). depicts site 974 that contained two vegetation zones, one moderately degraded and the other reference conditions so the two averaged together produced an overall wetland category of mildly impacted. Example b.) is indicative of how water quality changed annual at site 461 from 2012 to 2015 . Site 461 is the only site in the figure containing inter-annual data included as an example 


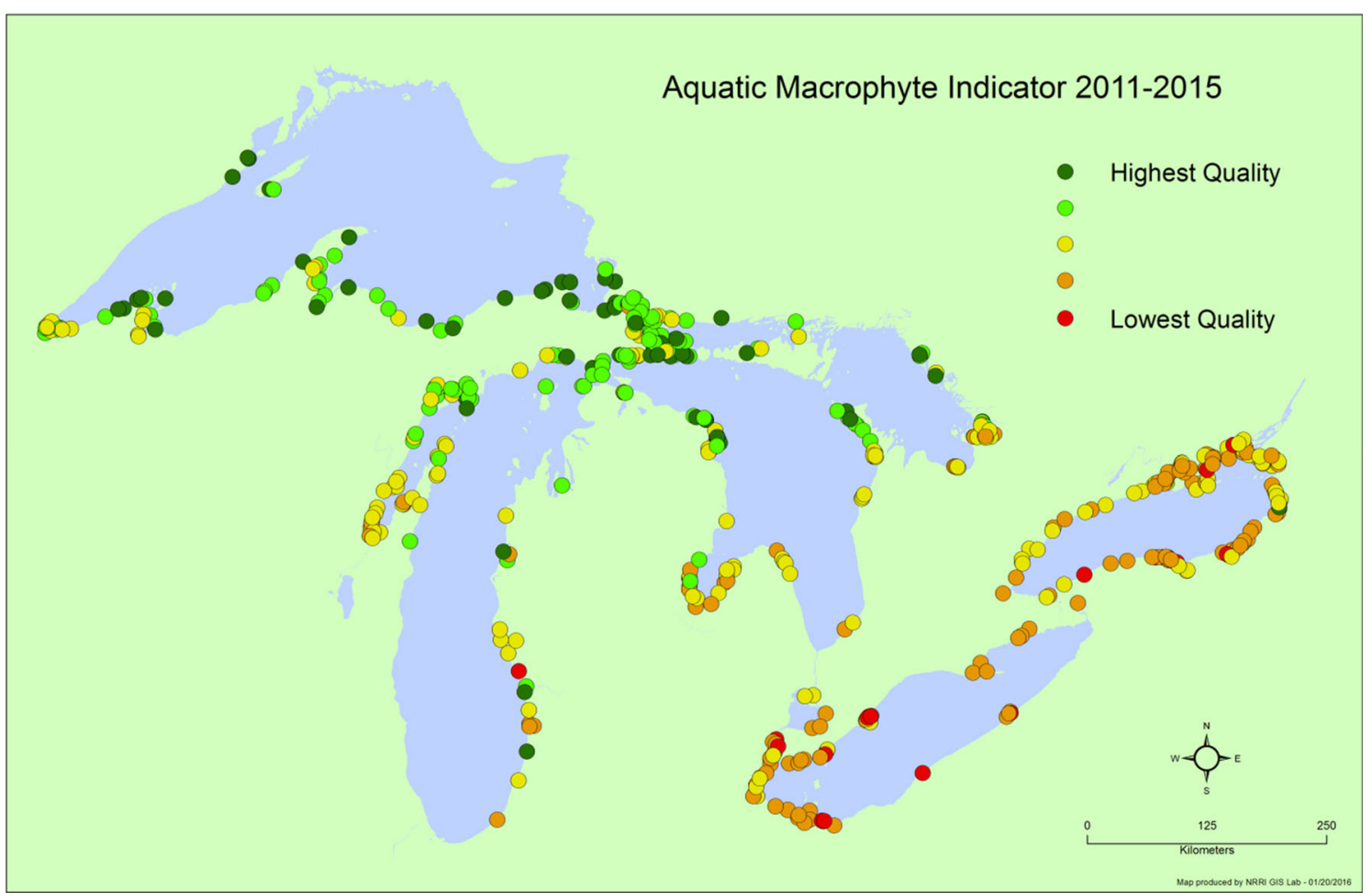

Fig. 6 Vegetation metrics from 2011 to 2015 showed a very strong decreasing disturbance gradient from south to north. Red indicates low quality and green represents high quality

also collected from plant zones other than outer Schoenoplectus, inner Schoenoplectus, and wet meadow but were not included here because metrics specific to those zones were still under construction. However, these data can be accessed at http://greatlakeswetlands.org. This indicator did not reflect a clear gradient from south to north but instead

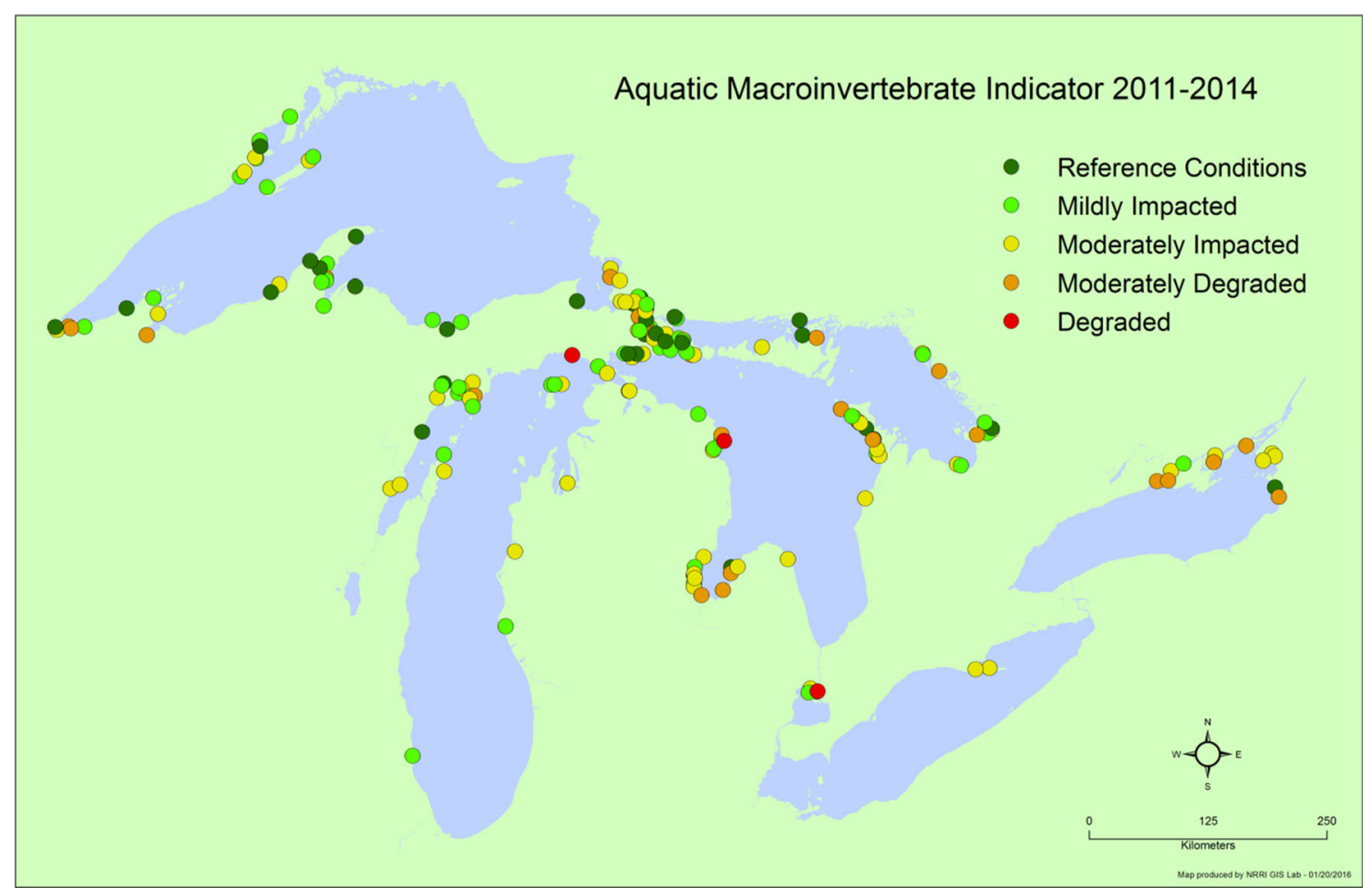

Fig. 7 Macroinvertebrate metrics were calculated for outer Schoenoplectus, inner Schoenoplectus, and wet meadow from 2011 through 2014 with green representing reference conditions and red degraded 
reflected localized conditions in the portion of the wetland that was inundated with water. Habitat quality was standardized to some degree by maintaining specific plant zones or morphotypes. However, microhabitat conditions changed within a given plant zone to some degree reflecting anthropogenic disturbance. The invertebrates integrated water quality temporally but in a localized way since mobility is limited.

\section{Fish}

Fish indicators from 2011 to 2015 showed somewhat of a gradient from north to south with increasing disturbance (Fig. 8). Fish metrics were calculated from data collected in Typha, submersed aquatic vegetation (SAV), Schoenoplectus, and lily (Nuphar and Nymphea). Fish indicators reflected a moderate scale of disturbance between the much localized invertebrate indicators and the regional/large scale vegetation indicators while incorporating water quality both locally and regionally.

\section{Anurans}

Anuran indicators measured from 2011 through 2015 were developed separately for southern and northern regions (Fig. 9). The vast majority of the sites fell between best and poorest conditions in both regions. Anuran indicators were placed into only three categories because the sensitivity of these indicators is low due to a limited number of species in the basin. Anurans reflect poorly as indicators of ecological integrity of the entire wetland but are organisms of interest, and therefore, are included in our monitoring design.

\section{Birds}

Bird indicators were calculated from data collected during 2011 through 2015 (Fig. 10). Unlike, chemical/physical, plants, invertebrates, and fish, birds did not indicate a gradient from north to south. In fact, some of the northern most sites located on Lake Superior were deemed degraded by these indicators. Birds were responding substantially to wetland size and possibly to the productivity of the system. Therefore, small low productivity wetlands with high water quality and little human influence may be unattractive to key bird species.

\section{Discussion}

This paper brings together and describes for the first time all of the components of the most comprehensive coastal wetland monitoring program ever attempted. Such a huge endeavor will benefit from ongoing improvements as discussed for certain aspects below. However, the current field methods and indicator calculations, which have been vetted and developed by an impressively large team of researchers over many years, are extremely well-supported and are currently providing

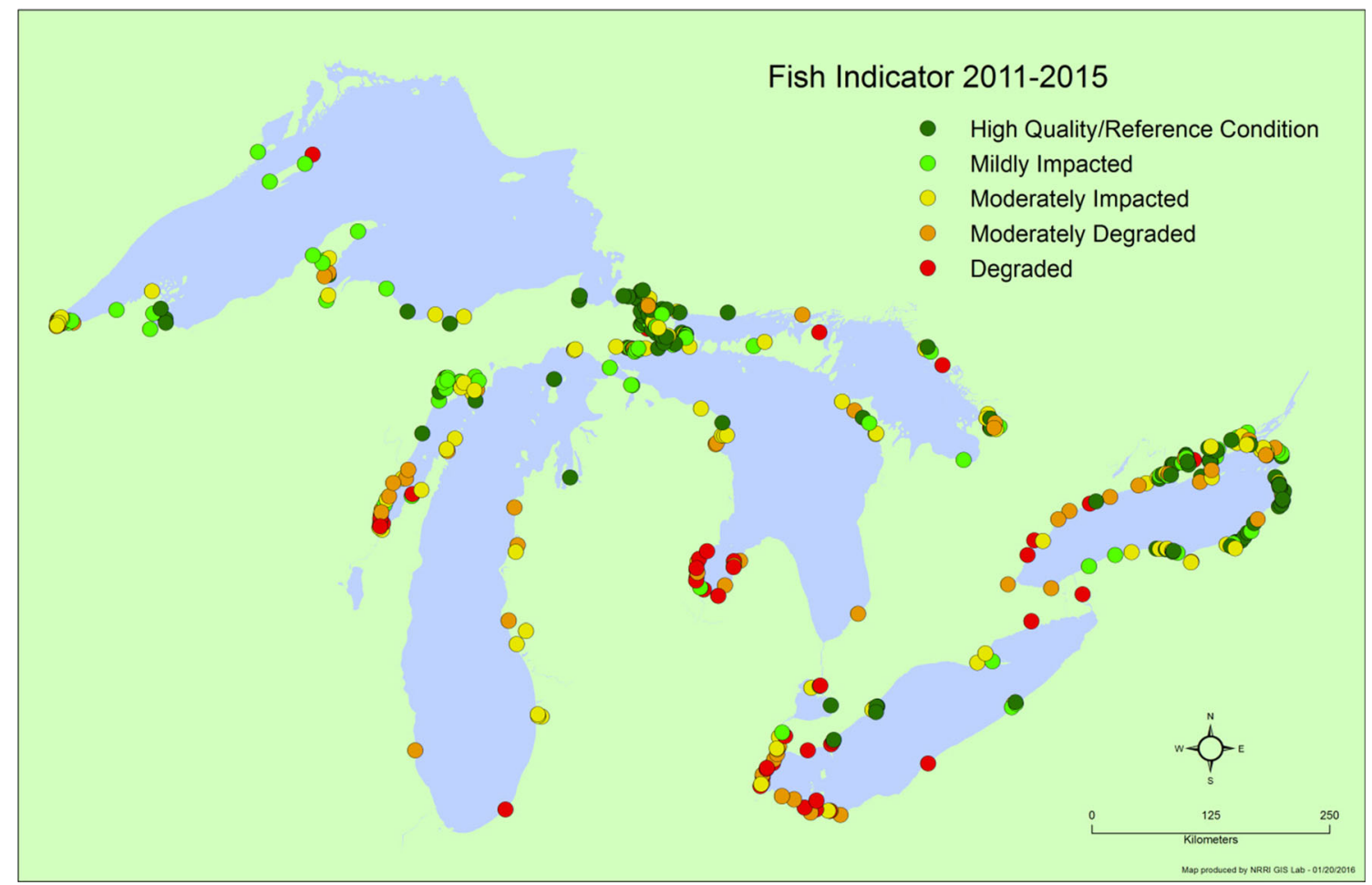

Fig. 8 Fish indicators from 2011 to 2015 showed somewhat of a gradient from north to south with increasing disturbance. Green represents reference conditions and red degraded 


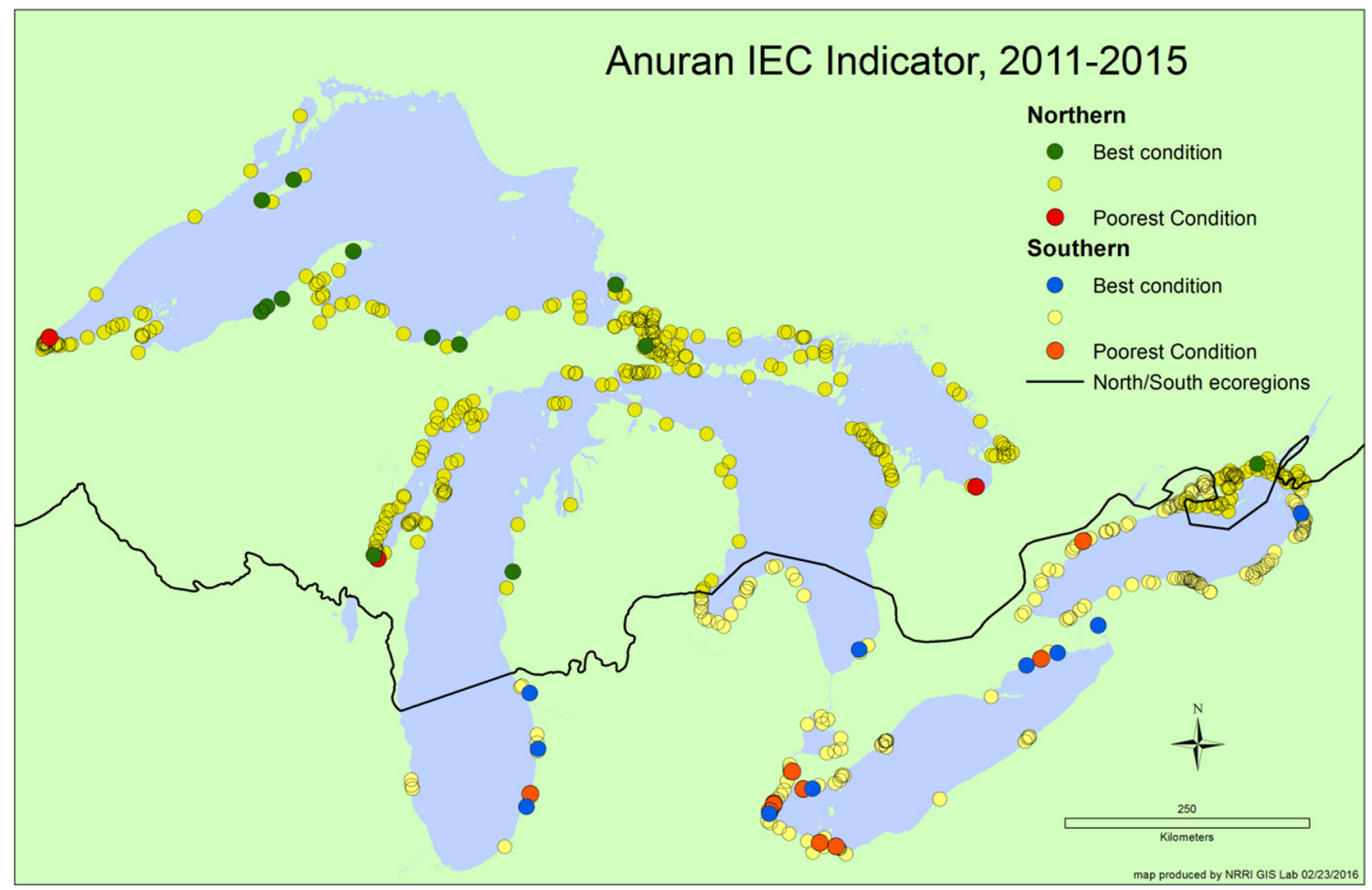

Fig. 9 Anuran indicators measured from 2011 through 2015 were developed separately for southern and northern regions. The best conditions in the north and south are represented by green and blue respectively. Poorest conditions in both regions are indicated with red circles

critical information at a multitude of levels for Great Lakes conservation. The general approach, methods, and indicators can also be emulated by others to monitor wetlands or other ecosystems in other locations globally.

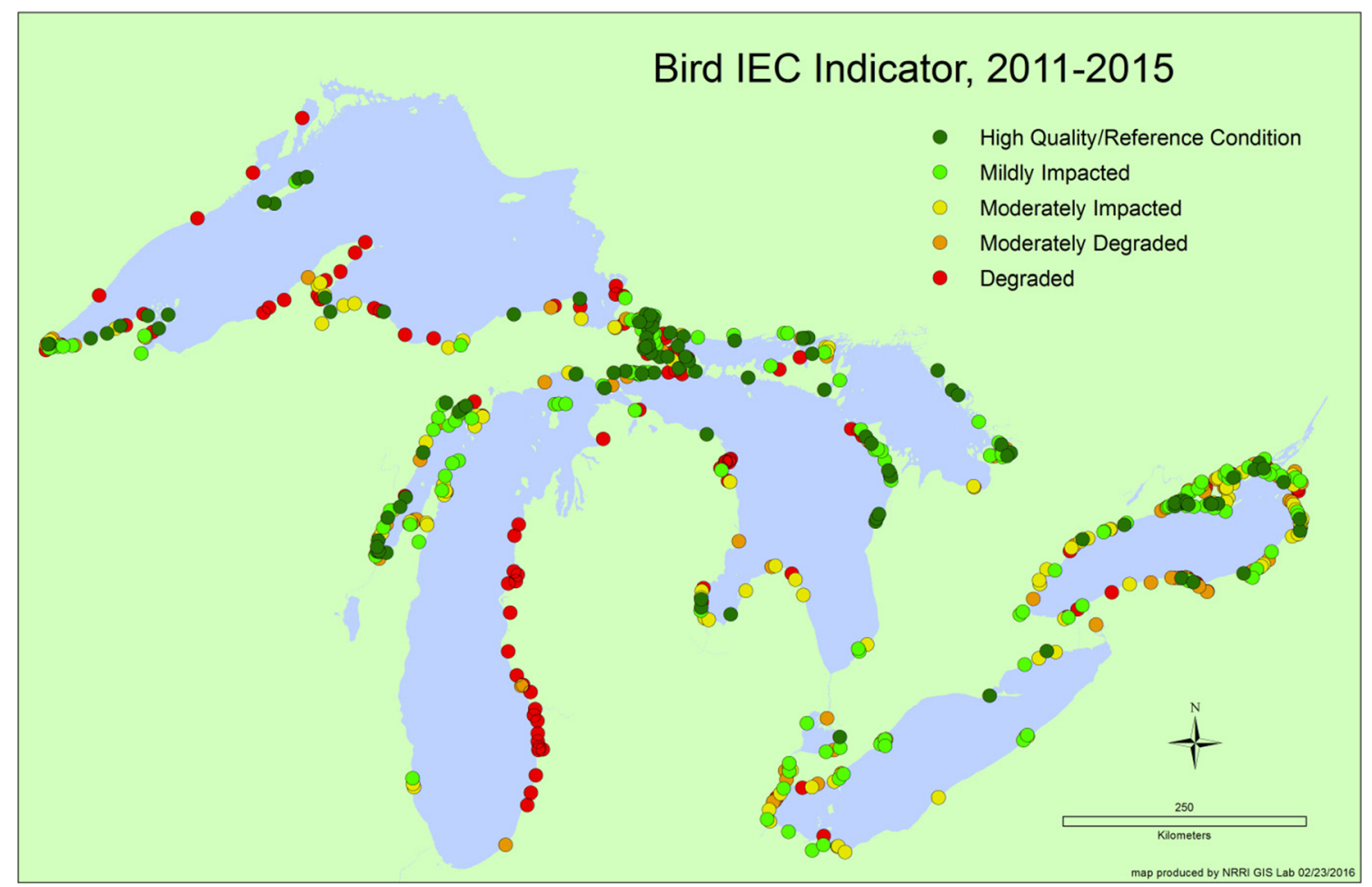

Fig. 10 Bird indicators were calculated from data collected during 2011 through 2015 with green representing high quality and red degraded 


\section{Application of Methods}

The methods described above represent the minimum recommended sampling effort required for computation of each indicator; ideally, all indicators can be calculated to determine the condition of each Great Lakes wetland. These methods were developed to minimize effort and resources while maintaining reliable, statistically robust results. We recommend sampling for and calculating as many wetland condition indicators as possible for each wetland.

\section{Interpretation of Indicator Scores}

Interpreting the results of each indicator required consideration of the nature of the assigned indicator scores and the scale of disturbance indicated. During development, each indicator was calibrated to a gradient of known anthropogenic disturbance (Uzarski et al. 2005), thereby making it possible to understand the most probable set of causes for the resulting score or ultimate cause of the poor condition. Stressor identification is aided by chemical and physical covariates collected at each wetland that serve to further explain variation in these data.

The interpretation of wetland quality, assigned by different organism-based indicators, can be confounding when separate indicators applied to a single wetland result in conflicting scores. For example, the vegetation-based indicator may assess a wetland as having "low" quality, but the fish- or bird based indicator may assess the same wetland as being "mildly impacted". These discordant assessments are likely associated with spatial and temporal scale and the nature of the anthropogenic disturbances affecting the wetland as well as the different effects on various taxonomic groups; e.g. the vegetation-based indicator is weighted strongly by the presence and abundance of invasive plant species, which is not always linked directly to water quality. In contrast, for a wetland in which the fish community is indicated as being of low quality and the vegetation of high quality, the fish communities may reflect anthropogenic influences on the nearshore and open water zones of the wetland, or this could simply be the result of low water levels at the time of sampling. These influences may include, but are not limited to boat channels, agricultural drainage ditches, industrial effluent, and other disturbances that by-pass the higher elevation portions of wetlands (Uzarski 2009). A single wetland is comprised of components that represent a hydrological continuum from terrestrial to aquatic habitat, and therefore, one should not expect anthropogenic disturbance to be consistently distributed throughout a wetland nor should different taxonomic groups respond the same way. This sampling program captures indicators that represent many temporal and spatial components of the wetland, thereby ensuring a multi-faceted assessment of its condition. For this reason, metrics were not developed using a single disturbance gradient because different taxonomic groups respond to different combinations of limnological, structural, toxicological, and landscape factors inherent within each wetland (Uzarski et al. 2005; Burton et al. 2008).

Additional considerations when interpreting indicator data are the life history and mobility of indicator organisms and how they respond to anthropogenic disturbance. Plant communities are potentially altered by anthropogenic influences more slowly than faunal communities due to their sessile nature and lag times in response. The alteration of these plant communities is also typically linked to the spread of invasive species. This suggests that the vegetation-based indicator detects anthropogenic influences at broader spatial and temporal scales. This was also shown to be the case with anurans (Price et al. 2004) and breeding birds (Hanowski et al. 2007a; Howe et al. 2007a) in wetlands of the Great Lakes. Conversely, macroinvertebrates have relatively short lifecycles, limited mobility in the larval form, and may indicate anthropogenic influences at finer scales. With this understanding, macroinvertebrate-based indicators may serve as a fine-scale assessment of quality within broader vegetation-based quality categories and be more specific to water quality. Furthermore, one indicator may be an early detection warning of a disturbance that may eventually affect other taxa in the wetland and across the region.

\section{Influence of Water-Level Fluctuations on Diagnosis of Wetland Condition}

Great Lakes coastal wetlands are dynamic systems that are significantly influenced by the water levels of the Great Lakes (Burton 1985; Wilcox et al. 2007; Uzarski 2009). The Great Lakes coastal wetland vegetation zones are organized in a replacement series along a hydrological gradient ranging from dry terrestrial soils to aquatic habitat several meters deep. The position of each zone along this gradient, within each wetland, is primarily governed by sources of naturally occurring disturbance in the form of variation in water depth and wave exposure (Burton 1985; Wilcox and Nichols 2008; Burton and Uzarski 2009; Uzarski 2009). Fluctuations in water levels cause plants, animals and physico-chemical characteristics to shift along this gradient, with different taxa relocating at different rates, depending on their inherent dispersal capabilities (Gathman et al. 2005; Gathman and Burton 2011). The persistence of some vegetation zones depends entirely upon minimum levels of wave energy and water-level fluctuations. Water levels in Lakes Huron and Michigan declined substantially beginning in 1999 causing many lacustrine fringing wetlands that were previously inundated with deep water to become shallower or dewatered and less exposed to wave energy (Uzarski et al. 2009). As a result, vegetation zones and faunal communities shifted lakeward, changed in size, or ceased to exist. Alternatively, during 
periods of extreme high lake levels, some vegetation zones may not be present at all. Additionally, anthropogenic disturbances may exert greater effects during periods of extreme water levels. Shoreline hardening and installation of seawalls have been common during past periods of high-water levels, while dredging of channels, tilling, and mowing are common practices during low-water-levels periods (Uzarski et al. 2009; Schock et al. 2014). This variation presents a limitation for potential assessment techniques, unlike ours, that rely on returning to specific sampling points over multiple years because naturally occurring environmental variation cannot be differentiated from anthropogenic disturbance.

Methods described herein do not depend on returning to the same sampling points since water levels of the Laurentian Great Lakes vary considerably. To control for natural disturbance, or water level fluctuation, organism-based indicators used were adaptable to changing water-level regimes and subsequent shifts in wetland position. By using vegetation-typespecific faunal indicator metrics, the methods described above are adaptable to these changes (Uzarski et al. 2004, 2005; Albert 2008). Vegetation-based indicators are much more sensitive to wide natural fluctuations in water levels because deep waters and dewatered shorelines can alter plant communities dramatically from year to year with no change in anthropogenic disturbance (Wilcox et al. 2002). However, the drawback is that metrics must be established for all vegetation zones and for locations where vegetation has been removed via human alterations. Thus, development of suitable vegetation-based metrics is central to effective assessment. In fact, all indicator groups and metrics will continue to be refined indefinitely as more data are generated. The key is maintaining consistent sampling protocols so that data are transferable and robust over space and time.

\section{Continued Development and Calibration}

The fish and invertebrate methods have been developed and calibrated for most geographical regions and wetland types in the Great Lakes basin, but further development of habitat specific metrics is needed to meet basin-wide applicability. This development process has been made more effective by standardizing data-collection techniques and by using multiple gradients of anthropogenic disturbance (Danz et al. 2005; Uzarski et al. 2005, 2014). Further development is needed in the following areas: expansion of vegetation zone-specific indicators for use across all vegetation zones, calibration of indicators to include additional wetland types (e.g., drowned river mouth wetlands for invertebrate-based indicators), development of more functional indicators (Steinman et al. 2012), and efforts to include future anthropogenic disturbance severity (e.g., climate change). All indicators and metrics should continuously be tested and improved as more data are generated.
Acknowledgments Neil Schock, David Schuberg, Alexandra Bozimowski, and Thomas Langer reviewed the manuscript. We also thank the editor, associate editor and two referees for their substantial contributions. Drs. Leah Minc and Alan Tepley assisted in the data analyses that led to the current plant metrics. The research was carried out by researchers from 11 US and Canadian universities, the Michigan Department of Environmental Quality, the Canadian Wildlife Service, and Bird Studies Canada. Funding for this work was provided by the Great Lakes National Program Office under the United States Environmental Protection Agency, grant number GL-00E00612-0 as part of the US federal government's Great Lakes Restoration Initiative. Although the research described in this work has been partly funded by the United States Environmental Protection Agency, it has not been subjected to the agency's required peer and policy review and therefore does not necessarily reflect the views of the agency and no official endorsement should be inferred. This paper is Contribution Number 76 of the Central Michigan University Institute for Great Lakes Research and Contribution Number 613 of the Natural Resources Research Institute, University of Minnesota-Duluth.

Open Access This article is distributed under the terms of the Creative Commons Attribution 4.0 International License (http:// creativecommons.org/licenses/by/4.0/), which permits unrestricted use, distribution, and reproduction in any medium, provided you give appropriate credit to the original author(s) and the source, provide a link to the Creative Commons license, and indicate if changes were made.

\section{References}

Albert DA (2008) Chapter 3- Vegetation Community Indicators. In: Great Lakes Coastal Wetlands Monitoring Plan. Great Lakes Wetland Consortium, Great Lakes Commission

Albert DA, Minc LD (2004) Plants as indicators for Great Lakes coastal wetland health. Aquatic Ecosystem Health and Management 7(2): 233-247

Albert DA, Simonson L (2004) Coastal wetland inventory of the Great Lakes region (GIS coverage of U.S. Great Lakes: www.glc. org/wetlands/inventory.html), Great Lakes Consortium, Great Lakes Commission, Ann Arbor, MI

Albert DA, Wilcox DA, Ingram JW, Thompson TA (2006) Hydrogeomorphic classification for Great Lakes coastal wetlands. Journal of Great Lakes Research 31 (Supplement 1):129-146

Albert, DA, Tepley AJ, Minc LD (2007) Plants as indicators for Lake Michigan's Great Lakes coastal drowned river wetland health. In T.P. Simon and P.M. Stewart (Eds.), Coastal Wetlands of the Laurentian Great Lakes: Heath, Habitat, and Indicators, Authorhouse Press, Bloomington, IN

Anderson P, Davie RD (2004) Use of transparency tubes for rapid assessment of total suspended solids and turbidity in streams. Lake and Reservoir Management 20(2):110-120

APHA (2005) Standard Methods for the Examination of Water and Wastewater. 25th Edition. American Public Health Association

Bailey, RC, Norris RH, Reynoldson TB (2004) Bioassessment of freshwater ecosystems. Springer US

Bedford KW (1992) The physical effects of the Great Lakes on tributaries and wetlands. Journal of great Lake. Research 18:571-589

Burton TM (1985) Effects of water level fluctuations on Great Lakes coastal marshes. In: Coastal Wetlands, Lewis Publishers, Chelsea Michigan, pp 3-13

Burton TM, Uzarski DG (2009) Biodiversity in protected coastal wetlands along the west coast of Lake Huron. Aquatic Ecosystem Health and Management 12(1):63-76 
Burton TM, Uzarski DG, Gathman JP, Genet JA, Keas BE, Stricker CA (1999) The development of an index of biotic integrity for Great Lakes coastal wetlands of Lake Huron. Wetlands 19(4):869-882

Burton TM, Brazner JC, Ciborowski JJH, Grabas GP, Hummer J, Schneider J, Uzarski DG, editors (2008) Great Lakes Coastal Wetlands Monitoring Plan. Developed by the Great Lakes Coastal Wetlands Consortium, for the US EPA, Great Lakes National Program Office, Chicago, IL. Great Lakes Commission, Ann Arbor, Michigan, USA. 293 p

Calabro EJ, Murry BA, Woolnough DA, Uzarski DG (2013) Application and transferability of Great Lakes coastal wetland indices of biotic integrity to high quality inland lakes of Beaver Island in northern Lake Michigan. Aquatic Ecosystem Health and Management 16(3): 338-346

Cardinale BJ, Brady VJ, Burton TM (1998) Changes in the abundance and diversity of coastal wetland fauna from the open water/ macrophyte edge towards shore. Wetlands Ecology and Management 6(1):59-68

Chadde S (2011) A Great Lakes Wetland Flora. Third Edition. Pocketflora Press. United States of America, pp 649

Chin ATM, Tozer DC, Walton NG, Fraser GS (2015) Comparing disturbance gradients and bird-based indices of biotic integrity for ranking the ecological integrity of Great Lakes coastal wetlands. Ecological Indicators 57:475-485

Chow-Fraser P (2006) Development of the wetland water quality index for assessing the quality of Great Lakes coastal wetlands, in: T. Simon and T.P. Stewart (Eds.). Coastal Wetlands of the Laurentian Great Lakes: Health, Habitat and Indicators. Author House. Bloomington, IN, USA

Conway CJ (2011) Standardized north American marsh bird monitoring protocol. Waterbirds 34:319-346

Cooper MJ, Gyekis KF, Uzarski DG (2012) Edge effects on abiotic conditions, zooplankton, macroinvertebrates, and larval fishes in Great Lakes fringing marshes. Journal of Great Lakes Research 38(1): $142-151$

Cooper MJ, Lamberti GA, Uzarski DG (2014) Spatial and temporal trends in invertebrate communities of Great Lakes coastal wetlands, with emphasis on Saginaw Bay of Lake Huron. Journal of Great Lakes Research 40 (Supplement 1):168-182

Corkum LD (2010) Fishes of Essex County and Surrounding Waters: A comprehensive field guide to fishes in Canadian and adjacent American waters. Essex County Field Naturalists Club, Friesens Corporation, Altona, Manitoba, Canada

Crewe TL, Timmermans STA (2005) Assessing biological integrity of Great Lakes coastal wetlands using marsh bird and amphibian communities. Project\# WETLAND3-EPA-01 Technical Report. Bird Studies Canada, Canada

Croft MV, Chow-Fraser P (2007) Use and development of the wetland macrophyte index to detect water quality impairment in fish habitat of Great Lakes coastal marshes. Journal of Great Lakes Research 33: 172-197

Danz NP, Regal RR, Niemi GJ, Brady V, Hollenhorst T, Johnson LB, Host GE, Hanowski JM, Johnston CA, Brown T, Kingston J, Kelly JR (2005) Environmentally stratified sampling design for the development of Great Lakes environmental indicators. Environmental Monitoring and Assessment 102:41-65

DeLuca WV, Studds CE, Rockwood LL, Mara PP (2004) Influence of land use on the integrity of marsh bird communities of Chesapeake Bay. U.S.a. Wetlands 24:837-847

EC and CLOCA (Environment Canada, Central Lake Ontario Conservation Authority) (2004) Durham region coastal wetland monitoring project: year 2 technical report. Environmental Conservation Branch - Ontario Region, Downsview, ON

Etterson M, Niemi G, Danz N (2009) Estimating the effects of detection heterogeneity and overdispersion on trends estimated from avian point counts. Ecological Applications 19:2049-2066
Gathman JP, Burton TM (2011) A Great Lakes coastal wetland invertebrate community gradient: relative influence of flooding regime and vegetation zonation. Wetlands 31(2):329-341

Gathman JP, Albert DA, Burton TM (2005) Rapid plant community response to a water level peak in northern Lake Huron coastal wetlands. Journal of Great Lakes Research 31:160-170

Gnass Giese EE, Howe RW, Wolf AT, Miller NA, Walton NG (2015) Sensitivity of breeding birds to the "human footprint" in western Great Lakes forest landscapes. Ecosphere 6:art90

Grabas GP, Blukacz-Richards EA, Pernanen S (2012) Development of a submerged aquatic vegetation community index of biotic integrity for use in Lake Ontario coastal wetlands. Journal of Great Lakes Research 38:243-250

Hanowski J, Danz NP, Howe R, Niemi G, Regal R (2007a) Consideration of geography and wetland geomorphic type in the development of Great Lakes coastal wetland bird indicators. EcoHealth 4:194-205

Heath RT (1992) Nutrient dynamics in Great Lakes coastal wetlands: future directions. Journal of Great Lakes Research 18:590-602

Herman KD, Masters LA, Penskar MP, Reznicek AA, Wilhelm GS, Brodovich WW, Gardiner KP (2001) Floristic quality assessment with wetland categories and examples of computer applications for the state of Michigan. 2nd edition. Michigan Department of Natural Resources, Wildlife Division, Natural Heritage Program

Herricks EE, Schaeffer DJ (1985) Can we optimize biomonitoring? Environmental Management 9(6):487-492

Hilborn R, Mangel M (1997) The Ecological Detective: Confronting Models with Data (MPB-28) Princeton University Press. 336 pp.

Holm E, Mandrak NE, Burridge ME (2009) The ROM Field Guide to Freshwater Fishes of Ontario, Royal Ontario Museum. Guelph, ON., pp 462

Howe RW, Regal RR, Hanowski JM, Niemi GJ, Danz NP, Smith CR (2007a) An index of ecological condition based on bird assemblages in Great Lakes coastal wetlands. Journal of Great Lakes Research 33(3):93-105

Howe RW, Regal RR, Niemi GJ, Danz NP, Hanowski JM (2007b) A probability-based indicator of ecological condition. Ecological Indicators 7:793-806

Hubbs CL, Lagler FK, Smith GR (2004) Fishes of the Great Lakes region (Revised Edition), University of Michigan Press. Ann Arbor, MI. xvii +276 pp.

Ingram J, Holmes K, Grabas G, Watton P, Potter B, Gomer T, Stow N (2004) Development of a coastal wetlands database for the Great Lakes Canadian shoreline. Technical report to Great Lakes Commission: WETLANDS2-EPA-03

Karr JR (1981) Assessment of biotic integrity using fish communities. Fisheries 6:21-27

Krieger KA, Klarer DM, Heath RT, Herdendorf CE (1992) Coastal wetlands of the Laurentian Great Lakes: current knowledge and research needs. Preface: a call for research on great Lake coastal wetlands. Journal Great Lakes. Research 18:525-528

Leveque C, Balian EV, Martens K (2005) An assessment of animal species diversity in continental waters. Hydrobiologia 542(2):39-67

Lougheed VL, Chow-Fraser P (2002) Development and use of a zooplankton index of wetland quality in the Laurentian Great Lakes basin. Ecological Applications 12(2):474-486

Martínez-Crego B, Alcoverro T, Romero J (2010) Biotic indices for assessing the status of coastal waters: a review of strengths and weaknesses. Journal of Environmental Monitoring 12(5):10131028

Matsuoka SM, Bayne EM, Solymos P, Fontaine P, Cumming SG, Schmiegelow FKA, Song SJ (2012) Using binomial distancesampling models to estimate the effective detection radius of point-count surveys across boreal Canada. Auk 129:268-282

Matsuoka SM, Mahon CL, Handel CM, Solymos P, Bayne EM, Fontaine PC, Ralph CJ (2014) Reviving common standards in point-count surveys for broad inference across studies. Condor 116:599-608 
McKee PM, Batterson TR, Dahl TE, Glooschenko V, Jaworski E, Pearce JB, Raphael CN, Whillans TH, LaRoe ET (1992) Great Lakes aquatic habitat classification based on wetland classification systems. In: Busch W-DN, Sly PG (eds) The development of an aquatic habitat classification system for lakes. CRC Press, Boca Raton, FL, USA, pp. 59-72

Merritt RW, Cummins KW, Berg MB (2008) An introduction to the aquatic insects of North America, fourth edn. Kendall/Hunt Publishing Co., Dubuque, IA

Mitsch WJ, Gosselink JG (1993) Wetlands. Van Nostrand Reinhold, New York

Niemi GJ, McDonald ME (2004) Application of ecological indicators. Annual Review of Ecology, Evolution, and Systematics 35:89-111

Niemi GJ, Kelly JR, Danz NP (2007) Environmental indicators for the coastal region of the north American Great Lakes: introduction and prospectus. Journal of Great Lakes Research 33:1-12

Price SJ, Marks DR, Howe RW, Hanowski JM, Niemi GJ (2004) The importance of spatial scale for conservation and assessment of anuran populations in coastal wetlands of the western Great Lakes. Landscape Ecology 20:441-454

Price SJ, Howe RW, Hanowski JM, Niemi GJ, Smith CR, Danz NP (2007) Are anurans of Great Lakes coastal wetlands reliable indicators of ecological condition? Journal of Great Lakes Research 33(3): 211-223

Rempel AR, Rempel AW, Cashman KV, Gates K, Page CJ, Shaw B (2013) Interpretation of passive solar field data with EnergyPlus models: un-conventional wisdom from four sunspaces in Eugene, Oregon. Building and Environment 60:158-172

Schock NT, Murry BA, Uzarski DG (2014) Impacts of agricultural drainage outlets on Great Lakes coastal wetlands. Wetlands 34:297-307

Seilheimer TS, Chow-Fraser P (2006) Development and use of the wetland fish index to assess the quality of coastal wetlands in the Laurentian Great Lakes. Canadian Journal of Fisheries and Aquatic Sciences 63:354-366

Simon TP, Stewart PM, Rothrock PE (2001) Development of multimetric indices of biotic integrity for riverine and palustrine wetland plant communities along southern Lake Michigan. Aquatic Ecosystem Health and Management 4:293-309

Smith-Cartwright LA, Chow-Fraser P (2011) Application of the index of marsh bird community integrity to coastal wetlands of Georgian bay and Lake Ontario, Canada. Ecological Indicators 11(5):1482-1486

SOLEC (2007) State of the Great Lakes. Environment Canada and United States Environmental Protection Agency. ISBN 978-0 662-47328-2. EPA 905-R-07-003. Cat No. En161-3/1-2007EPDF. http://www.epa.gov/solec/sogl2007/SOGL2007.pdf

Steinman AD, Ogdahl ME, Thompson K, Cooper MJ, Uzarski DG (2012) Water level fluctuations and sediment-water nutrient exchange in Great Lakes coastal wetlands. Journal of Great Lakes Research 38:766-775

Thorp JH, Covich AP (2010) Ecology and classification of north American freshwater invertebrates. 3rd Edition. Academic Press, San Diego, CA

Tozer, DC (2013) The Great Lakes Marsh Monitoring Program 19952012: 18 years of surveying birds and frogs as indicators of ecosystem health. Published by Bird Studies Canada, 10 pp. http://www.birdscanada.org/download/GLMMPreport.pdf

Uzarski DG (2009) Wetlands of Large Lakes. Encyclopedia of Inland Waters. (Gene E. Likens, Editor). Oxford: Elsevier. p. 599-606

Uzarski DG, Burton TM, Genet JA (2004) Validation and performance of an invertebrate index of biotic integrity for lakes Huron and Michigan fringing wetlands during a period of lake level decline. Aquatic Ecosystem Health and Management 7:269-288

Uzarski DG, Burton TM, Cooper MJ, Ingram J, Timmermans S (2005) Fish habitat use within and across wetland classes in coastal wetlands of the five Great Lakes: development of a fish-based index of biotic integrity. Journal of Great Lakes Research 31(supplement 1): $171-187$

Uzarski DG, Burton TM, Kolar RE, Cooper MJ (2009) The ecological impacts of fragmentation and vegetation removal in Lake Huron coastal wetlands. Aquatic Ecosystem Health and Management 12(1):45-62

Uzarski DG, Schock NT, Wheeler RL (2014). Indices of Biotic Integrity with Emphasis on Wetlands. Encyclopedia of Natural Resources. Taylor \& Francis doi:10.1081/E-ENRW-120051310

Venier LA, Holmes SB, Holborn GW, Mcilwrick KA, Brown G (2012) Evaluation of an automated recording device for monitoring forest birds. Wildlife Society Bulletin 36(1):30-39

Voss EG (1972a) Michigan Flora, Volume 1: Gymnosperms and Monocots. Cranbrook University Press. Oakland, MI, pp 1-5

Voss EG (1972b) Michigan Flora Part 1, Gymnosperms and Monocots. Cranbrook Institute of Science. Bloomfield Hills, Mi, USA. Bulletin 55

Voss EG (1985) Michigan Flora, volume 2: dicots. University of Michigan Press, Ann Arbor, MI

Voss EG (1996) Michigan Flora, Volume 3: Dicots. Concluded. University of Michigan Press, Ann Arbor, MI

Voss EG, Reznicek AA (2012) Field Manual of Michigan Flora. The University of Michigan Press. Ann Arbor, MI. pp 990

Wilcox DA (1995) The role of wetlands as nearshore habitat in Lake Huron. In M. Munawar, T. Edsall, and J. Leach (eds). The Lake Huron Ecosystem: Ecology, Fisheries and Management. Ecovision World Monograph Series, S.P.B. Academic Publishing, The Netherlands, pp 223-245

Wilcox DA, Nichols SJ (2008) The effect of water-level fluctuations on plant zonation in a Saginaw Bay, Lake Huron wetland. Wetlands 28: 487-501

Wilcox DA, Meeker JE, Hudson PL, Armitage BJ, Black MG, Uzarski DG (2002) Hydrologic variability and the application of index of biotic integrity metrics to wetlands: a Great Lakes evaluation. Wetlands 22(3):588-615

Wilcox DA, Thompson TA, Booth RK, Nicholas JR (2007) Lake-level variability and water availability in the Great Lakes. U.S. Geological Survey. Circular 1311

Wolter P, Niemi G, Johnston C (2006) Land use change in the U.S. Great Lakes basin 1992-2001. Journal of Great Lakes Research 32:607628

Woodward RT, Wui Y (2001) The economic value of wetland services: a meta-analysis. Ecological Economy 37(2):257-270 